\title{
Skill-Biased Technological Change and Homeownership
}

\author{
Alexis Anagnostopoulos, Orhan Erem Atesagaoglu, Eva Carceles-Poveda * \\ SUNY - Stony Brook
}

\begin{abstract}
In the United States, the residential housing market went through important changes over the period from the 1970s to the mid-1990s. Although the aggregate homeownership rate was relatively constant during that period, the distribution of homeownership rates by age changed in remarkable ways. While younger households saw substantial declines in homeownership rates, the opposite happened for older households. In this paper, we argue that the skill-biased technological change (SBTC) that began during the 1970s has been an important factor behind the observed change in the distribution of homeownership rates by age. We build a life cycle model in which skills are accumulated on-the-job through experience: learning by doing. Early in life, households have lower levels of skills and therefore lower earnings. SBTC increases the returns to skill, widening the wage gap between young and old ages. As a consequence, it takes more time for young households to become homeowners given frictions in financial markets (e.g. downpayment requirements) and housing markets (e.g. large and indivisible houses), in line with consumption smoothing behaviour. On the other hand, older households that could not afford a house before may now become homeowners, given higher returns to skill. Our analysis confirms this conjecture, namely, that SBTC shifts the distribution of homeownership from the young to the old.
\end{abstract}

Keywords: Homeownership, Incomplete Markets, Skill-Biased Technological Change.

JEL classification: E2.

${ }^{*}$ We would like to thank Hugo Benitez Silva, Tiago Cavalcanti, Thomas Crossley, Carlos Garriga, Gianmmario Impullitti, Fatih Karahan, Remzi Kaygusuz, Hamish Low, Warren Sanderson, Gianluca Violante, Hakki Yazici and Kamil Yilmaz, for useful comments and suggestions. We are also grateful to conference participants at the 2011 Midwest Macro meetings, 2010 EEA meetings, 2011 SED meetings, 2011 SAET meetings, 2011 CRETE Conference, as well as seminar participants at Bogazici University, University of Cambridge, CUNY, Central Bank of Turkey, University of Southampton, SUNY Stony Brook and TOBBETU. 


\section{Introduction}

In the United States, the residential housing market went through important changes over the period from the 1970s to the mid-1990s. Although the aggregate homeownership rate was relatively constant during that period, the distribution of homeownership rates by age changed in remarkable ways. Younger households experienced substantial declines in homeownership rates, whereas older households experienced an increase in homeownership rates. In this paper, we argue that the skill-biased technological change (SBTC) which occurred during the same period has been an important factor behind the observed change in the distribution of homeownership rates by age. We present a general equilibrium model that clarifies the proposed mechanism and carefully calibrate it to assess whether, and to which extent, SBTC can account for the observed changes in homeownership profiles.

The link between the age-profile of homeownership and SBTC goes through the profile of earnings by age. It has been extensively documented that the U.S. experience premium, defined as the return to labor market experience, increased substantially from the 1970s to the 1990s. ${ }^{1}$ This increase in the experience premium, together with the accompanying increase in education and occupation premia, have often been viewed as evidence of a latent SBTC which affected all dimensions of skill. ${ }^{2}$ In particular, it is argued that (i) the increase in relative returns to experience and (ii) the fact that experience is accumulated over the life cycle generates a steepening in life-cycle earnings profiles, widening the wage gap between young and old ages. In this paper, we follow this literature in considering SBTC as the driving factor for the observed increase in experience premia, and the accompanying steepening of the age-profile of earnings.

Given a steepening of earnings' profiles by age, a steepening of homeownership profiles by

\footnotetext{
${ }^{1}$ The term 'experience premium' refers to measures that estimate the wage gap between experienced-old workers and inexperienced-young workers. See Heathcote, Perri and Violante (2010) for a documentation of the evolution of the experience premium.

${ }^{2}$ See Hornstein, Krusell and Violante (2004) and Katz and Autor (1999) and the references therein. The latter also discusses alternative theories.
} 
age follows for two reasons. First, a steeper profile of earnings implies a steeper consumption profile for an individual. To the extent that owned houses are larger than rented ones, this implies a bigger gap between ownership when young and ownership when old. Second, consumption smoothing behavior leads young households to accumulate less savings early in the life-cycle. Given that buying a house requires a significant downpayment, lower savings early in the life cycle make it harder for young households to buy a house. Note that, these mechanisms implicitly assume frictions in the owned housing market (large indivisible houses) as well as frictions in financial markets (incomplete markets). Both of them result in a steeper homeownership profile. Depending on what happens to average household lifetime income, this mechanism has the potential to explain simultaneously the decrease in homeownership for the young and the concurrent increase for the old.

The two aspects described above, SBTC in labor markets and frictions in the housing and financial markets, are brought together in our theoretical economy. More concretely, we construct a general equilibrium, life-cycle model with housing and skill accumulation. Each household brings both raw labor (health, strength, etc.) and human capital (skills) to the labor market and earns separate wages for each type of labor. Skills accumulate exogenously, as result of the accumulation of work experience (learning-by-doing). ${ }^{3}$ SBTC increases the demand for skilled labor and, as a result, benefits older, more experienced workers who possess more skills. On the housing side, we allow households to decide whether to own or rent. Crucially, we introduce financial market frictions in the form of a downpayment requirement and no unsecured borrowing. In addition, owned houses are lumpy and there is a minimum size of house an individual can buy ${ }^{4}$.

Using this framework, we examine the response of households to SBTC, which is modelled as an exogenous increase in the demand for skills. This impulse increases the relative price (wage) of skills to raw labor, thus increasing the wage gap between young and old ages,

\footnotetext{
${ }^{3}$ Our modelling of the labor market follows closely Jeong, Kim and Manovskii (2010).

${ }^{4}$ Our modelling of the housing market follows closely Gervais (2002) and Nakajima (2010).
} 
since households have lower levels of skills early in life. As a result, households face a steeper profile of earnings and experience faster consumption growth over the life cycle. Importantly, earnings are lower at the early stage of life which, because of incomplete markets, translates to both lower consumption and lower savings. The first means that they are less likely to desire large enough housing services to be able to own a house. The second means that it will take them longer to accumulate sufficient savings for a downpayment. Older households on the other hand see an increase in their earnings and this makes them willing to live in a large enough house to be able to own. In conclusion, our numerical results confirm the conjecture above, namely that SBTC shifted the distribution of homeownership from the young to the old. Overall, the model can account for $96 \%$ of the total decrease in homeownership for the younger generations (20-44 year old) and for $42 \%$ of the total increase in homeownership of the older generations (60-79 year old).

In addition to SBTC, our benchmark calibration takes into account the decrease in mortality rates observed in the US between the 1970s and the 1990s. To separate the effects of mortality from those of SBTC, we have also considered an alternative calibration where these mortality changes are shut down. Mortality changes bring the model closer to the data in terms of the aggregate homeownership rate, which was approximately constant during the period of study. ${ }^{5}$ Mortality does not significantly affect the steepness of the homeownership profiles, which implies that SBTC is its cause in our model.

Our paper is closely related to a growing literature on housing and homeownership. Gervais (2002) and Nakajima (2010) are interested in the effects of taxation on aggregate homeownership. Fang Yang (2009) and Diaz and Luengo-Prado (2010) investigate how housing affects the life cycle properties of consumption and wealth respectively. In a series of papers, Chambers, Garriga and Schlagenhauf $(2009,2011)$ provide explanations for the significant changes in aggregate homeownership both in the 1940s and in the late 1990s. None

\footnotetext{
${ }^{5}$ Numerous other factors could have affected the level of homeownership profiles by age without directly affecting the slope. Since our focus is on the steepness of the life cycle profile, we refrain from entertaining alternative explanations.
} 
of these papers focus on the profile of homeownership by age. This task is taken up by Fisher and Gervais (2011), who focus on the decrease in ownership amongst younger households only. Their paper is the one that is most closely related to ours. Their explanation is based on two factors: increased idiosyncratic risk and a trend towards later marriage. They argue forcefully that there is a clear empirical relation between homeownership and both risk and marriage. Their calibrated model closely matches the experience of young households observed in the data. Our explanation through the SBTC is, in this sense, complementary to their work. In addition, SBTC provides a mechanism that can simultaneously cause a decrease in homeownership for the young and an increase in homeownership for the old. Thus we can also shed some light on the reasons underlying the second observation. Note, however, that the increase in homeownership amongst older households can only be partially explained by our model. As discussed in Fisher and Gervais (2011), a significant part of the observed increase for the old must arise from decisions made earlier in life not captured in our model. It is thus reasonable to expect that our model would explain only a fraction of that increase.

Our paper is also related to a recent literature aiming to provide theoretical foundations for the connection between SBTC and the increase in the experience premium. Aghion, Howitt and Violante (2002) argue that the new technology introduced beginning in the 1970 s is of a general purpose type. What this means is that skills acquired while working in one job or sector are now more transferable to other jobs/sectors. Accordingly, an individual with many years of experience in the labor market has acquired skills that are more valuable compared to before SBTC. As a result, the experience premium has risen. Note that theirs is a long run argument in spirit, in the sense that they compare two economies, one with the old technology and one with the new technology, and does not rely on the transition period. In this sense, this is most closely related to our modelling of SBTC. We abstract from the specific mechanism involved and take a reduced form modelling approach in the spirit of Jeong et al. (2010)'s analysis of the price of experience. Weinberg (2005) and 
Violante (2002) provide arguments for why SBTC could have led to a rise in experience premia even in the short run, i.e. while the new technology was diffusing in the economy. Weinberg (2005) provides evidence that older workers adopted the use of computers faster than younger ones. ${ }^{6}$ Violante (2002) argues that relatively younger workers have stronger incentives to abandon their accumulated skills from the old technology and move to the new technology sector. To the extent that older workers remain in the old sector and do not lose their skills, this also leads to a temporary increase in experience premia. ${ }^{7}$

The paper is organized as follows. Section 2 discusses the empirical evidence on the changes in the homeownership distribution between the 1970s and the 1990s. Section 3 presents the model and Section 4 defines the recursive competitive equilibrium. Section 5 presents the calibration and quantitative results. Section 6 summarizes and concludes.

\section{Changes in the Homeownership Distribution}

Figure 1 depicts the aggregate homeownership rate between 1968 and 2005 using data from the United States Statistical Abstract. It illustrates what the housing literature has come to consider a 'stylized fact', namely that the recent boom in US homeownership rates from the mid-1990s onwards was preceded by at least two decades of stagnation. Segal and Sullivan (1998), Li (2005) and Garriga, Gavin and Schlagenhauf (2006), amongst others, have shown that this is borne out of CPS data, PSID data as well as the Housing Vacancy Survey of the Census Bureau. Although the exact level of the homeownership rate varies slightly depending on the data source and the exact sample period one chooses, that level has remained close to an average of roughly $64 \%$ from the 1970 s up to the mid-1990s. Despite a variety of policies (and market innovations) aimed at raising homeownership, there is no discernible upward trend. On the contrary, by the mid 90s aggregate homeownership was slightly (approximately one percentage point) less than it was in the mid 70s.

\footnotetext{
${ }^{6}$ This is true for high school graduates, but the opposite is true for college graduates. However, high school graduates make up the majority of the workforce.

${ }^{7}$ For an authoritative survey of this literature see Hornstein et al. (2004).
} 
A growing literature addresses the dynamics of aggregate homeownership and, in particular, seeks to understand the underlying causes of the secular increase that began in the mid 90s. Proposed explanations include tax policies, government regulation and homeownership assistance programs, financial innovation in mortgage markets as well as demographic changes. Perhaps the most comprehensive study can be found in Chambers, Garriga and Schlagenhauf (2009). We focus instead on the period before the mid 90s, when aggregate homeownership rates were relatively stable. This stability masks an interesting pattern in the dynamics of homeownership at a more disaggregated level.

Table 1 summarizes the changes in the age distribution of homeownership rates between the 1970s and 1990s using data from the March Current Population Survey (CPS). It compares average homeownership rates by age groups across two periods: 1976 to 1978 (labelled 1970s) and 1994 to 1997 (labelled 1990s). ${ }^{8}$ The reported rates are closely in line with those reported by Segal and Sullivan (1998) and by Fisher and Gervais (2011). The last row of Table 1 displays the aggregate homeownership rate, which was $65.7 \%$ in the first period and $64.4 \%$ in the second. The overall average for the period between 1976 and 1997 is $64.3 \%$. Looking at homeownership rates by age reveals a substantial change in the age composition of homeownership. ${ }^{9}$ Ownership rates have fallen for households where the head is less than 49 years old and increased for households where the head is more than 55 years old. The magnitudes of these changes are substantial. Rates for households in their late twenties and early thirties have dropped by close to ten percentage points and rates for households above 65 have risen by a similar magnitude. The same pattern can be seen in Figure 2, which is the graphical representation of Table 1. Evidently, the age-profile of homeownership has steepened.

\footnotetext{
${ }^{8}$ Homeownership data are available in the CPS starting in 1976 . In addition, for the years 1979 to 1982, there seem to be problems with the ownership data in the CPS. See Segal and Sullivan (1998) for a confirmation of this observation and a proposed explanation. We follow their practice in ignoring the data for these years throughout the paper. More details about the data are provided in Appendix A.

${ }^{9}$ For earlier documentation of this fact, see Segal and Sullivan (1998), Li (2005), Garriga, Gavin and Schlagenhauf (2006), and Fisher and Gervais (2011).
} 
These numbers represent two snapshots at two different points (more precisely periods) in time. Figure 3 also presents the year-to-year evolution of homeownership rates for 'young' and 'old' households. These time series reveal an additional feature of the change in age distribution from the 70 s to the 90 s. They indicate that this change has happened in a continuous fashion throughout the two decades. In turn, this suggests that one-time policy changes, such as those considered in the literature on the dynamics of aggregate homeownership, cannot be the main underlying cause of the shift in the distribution of ownership rates. This paper's contention is that a strong candidate can be found in the labor market changes that resulted from the latent SBTC widely believed to have occurred during the same period.

\section{The Model}

Time is discrete. At each point in time, the economy is populated by $I$ overlapping generations of households, a real estate sector which provides rental homes, firms producing non-housing goods and a government which runs a pay-as-you-go social security. There are two consumption goods, housing services and non-housing goods, and two assets, financial assets and houses. In what follows, we describe each agent in turn.

\subsection{Households}

Demographics. Households are born at age 1 and can live up to age $I$. Retirement is mandatory at age $I_{r}$, with $1<I_{r}<I$. Households of age $i \leq I_{r}$ are called workers and those with age $i>I_{r}$ are called retirees. Each agent faces a positive probability of early death which is exogenous and independent of household characteristics other than age. The probability of surviving from age $i-1$ to age $i$ is denoted by $\psi_{i} \in[0,1]$, with $\psi_{1}=1$ and $\psi_{I+1}=0$. Due to the probability of death, there are accidental bequests which are distributed as assets to the surviving households. For calibration purposes, a fraction of these bequests is allocated to the new cohort. The remainder is distributed equally across 
all generations, yielding an amount $\operatorname{tr}$ per agent.

Preferences. In each period of its life cycle, a household receives income and decides how much to consume and how much to save in order to maximize expected discounted lifetime utility

$$
E \sum_{i=1}^{I} \beta^{i-1}\left(\Pi_{k=1}^{i} \psi_{k}\right) u\left(c_{i}, d_{i}\right)
$$

where $\beta$ is the time-discount factor, $c_{i}$ is consumption of non-housing goods and $d_{i}$ is consumption of housing services. Housing services can be obtained by either owning a house or renting a house from real estate firms. The expectation operator $E$ is over two sources of (uninsurable) idiosyncratic risk: mortality risk and labor income risk. The instantaneous utility function $u: R^{2} \rightarrow R$ is assumed to be strictly increasing and strictly concave in both arguments.

Income. Household income arises from different sources: after tax wage income or retirement benefits, asset returns and inherited bequests.

Retirement benefits $b_{i}$ are only received by retirees

$$
b_{i}=\left\{\begin{array}{cl}
0 & \text { if } i \leq I_{r} \\
b & \text { if } i>I_{r}
\end{array}\right.
$$

They are paid by the government and financed through a proportional payroll tax (more on this in the government section below).

Wage income is only earned by workers. Since the modelling of wages over the life cycle is central to the SBTC idea proposed in this paper, we describe this in detail. ${ }^{10}$ Each worker is endowed with both raw labor (strength, health, etc.) denoted by $u$ and human capital (skills, knowledge, etc.) denoted by $h .{ }^{11}$ These two factors are treated as separate and are assumed to earn separate wages in the market, $w_{u}$ and $w_{h}$ respectively. The overall wage income of a

\footnotetext{
${ }^{10}$ This way of modelling wages has been used among others by Guvenen and Kuruscu (2009) and Jeong et al. (2010).

${ }^{11}$ We use the terms 'human capital' and 'skills' interchangeably.
} 
worker is just the sum of the two types of income. The endowment of raw labor is constant over the life cycle and equal for all workers, whereas human capital varies exogenously over the life cycle. The underlying idea is that workers accumulate skills through learning-by doing and is motivated by the observation of substantial returns to experience. In this model, workers supply hours inelastically (i.e. work full time), implying that everyone accumulates skills in the same way. However, the presence of overlapping generations implies that there will be heterogeneity in skill levels in the population arising from the age/experience distribution at any point in time. Additional heterogeneity is introduced through stochastic productivity shocks $e$ to the efficiency of labor supplied to the market. The productivity shocks $e \in\left\{e_{1}, e_{2}, \ldots, e_{n}\right\}$ are generated by a stationary Markov transition matrix $\Pi$ that is identical across agents and over the life cycle. The total wage income of an individual of age $i$ is thus given by

$$
w_{i}=\left\{\begin{array}{cl}
e\left(w_{u} u+w_{h} h_{i}\right) & \text { if } i \leq I_{r} \\
0 & \text { if } i>I_{r}
\end{array}\right.
$$

To reduce notation, we define $y_{i}$ to be non-asset income after taxes

$$
y_{i}=\left\{\begin{array}{cl}
\left(1-\tau_{s}\right) e\left(w_{u} u+w_{h} h_{i}\right) & \text { if } i \leq I_{r} \\
b & \text { if } i>I_{r}
\end{array}\right.
$$

where $\tau_{s}$ is the social security tax rate.

Households also receive asset income. Recall, that a household has a portfolio allocation decision to make. In particular, it can choose to allocate wealth to financial or to housing assets. Since holding housing assets means being a homeowner, this portfolio decision is intricately related to the homeownership decision discussed below. Owning a house does not generate income explicitly, but households do receive income from holding financial assets $a$. In particular, financial assets earn an interest rate $r$ so that the overall asset income earned (plus principal) is $(1+r) a$. Note that this can, in principle, be negative if the household is 
in debt.

\subsection{Real Estate Sector}

Household savings into financial assets are channeled towards the two production sectors. This section describes the real estate sector, which produces rental housing services. The next section describes the sector which produces the non-housing consumption good.

Firms in the real estate sector operate in competitive markets and produce housing services using capital rented from the households. In particular, they rent an amount of capital $D_{r}$, which they transform into houses using a one-to-one production function. They subsequently rent these houses to interested households at a price $q$, denominated in units of the non-housing consumption good. At the end of the period, the intermediaries are left with the stock of houses net of depreciation and they pay principal plus interest $(1+r) D_{r}$ back to the households. The problem of a firm is thus:

$$
\max _{D_{r}}\left\{q D_{r}+\left(1-\delta_{d r}\right) D_{r}-(1+r) D_{r}\right\}
$$

Note that, in addition to being the stock of rental housing capital for this period, $D_{r}$ also represents the aggregate supply for rental housing services due to the one-to-one production function assumption. Optimization by intermediaries relates rental prices $q$ to interest rates $r$ according to

$$
q=r+\delta_{d r}
$$

This implies that renters pay the financial and maintenance (depreciation) cost for the value of the house they rent. The supply of rental housing services is perfectly elastic, so the equilibrium level of rental housing services (and rental housing stock) is entirely demand determined. 


\subsection{Non-Housing Good Producing Firm}

The non-housing consumption good is produced and supplied by firms operating in perfectly competitive markets. The representative firm in this sector produces output using a neoclassical, constant returns to scale technology:

$$
Y=A K^{\alpha} L^{1-\alpha}
$$

where $A$ is total factor productivity (TFP), $K$ is aggregate non-housing capital, which depreciates at the constant rate of $\delta_{k}$, and $L$ is a composite measure of aggregate efficiency units of labor, which is obtained by combining aggregate raw labor $U$ and the aggregate stock of skill $H$ as follows

$$
L \equiv \gamma U+(1-\gamma) H
$$

Note that this is a special case of the production function used in Krusell, Ohanian, Rios-Rull and Violante (2000). The parameter $\gamma$ captures the relative importance of skill and will be used to capture the skill-biased nature of technological change. Specifically, we model SBTC as a decrease in $\gamma$ and we assume that skill corresponds to experience. This way of modelling experience premia follows Jeong et al. (2010) and Guvenen and Kuruscu (2009, 2012). The firm chooses its demand for raw labor $U$, for skill $H$ and for capital $K$ to maximize period profits

$$
\begin{gathered}
\max _{\{H, U, K\}} A K^{\alpha} L^{1-\alpha}-w_{u} U-w_{h} H-\left(r+\delta_{k}\right) K \\
\text { s.t. } L=\gamma U+(1-\gamma) H
\end{gathered}
$$

taking the factor prices $w_{u}, w_{h}$ and $r$ as given. The optimal choice by firms leads to the 
familiar factor demand functions

$$
\begin{aligned}
r & =\alpha A\left(\frac{K}{L}\right)^{\alpha-1}-\delta_{k} \\
w_{u} & =\gamma(1-\alpha) A\left(\frac{K}{L}\right)^{\alpha} \\
w_{h} & =(1-\gamma)(1-\alpha) A\left(\frac{K}{L}\right)^{\alpha}
\end{aligned}
$$

The last two conditions imply that the relative price of skill is governed by $\gamma$

$$
\frac{w_{h}}{w_{u}}=\frac{1-\gamma}{\gamma}
$$

Thus, a decrease in $\gamma$ increases the relative price of skill regardless of any other general equilibrium effects.

\subsection{Households' Problem}

Total Wealth and State Variables. At any age $i$, an individual chooses to leave a total amount of wealth $x_{i+1}$ for the next period of their life. The individual can choose the allocation of this wealth between a house and financial assets after the realization of uncertainty next period. That is, the household does not commit to a specific composition of $x_{i+1}$ between financial assets and housing assets in advance (at age $i$ ). This simplifying assumption allows us to only keep track of $x$ as a state variable instead of having to keep track of both $a$ and housing assets. ${ }^{12}$ Apart from $x$, a household starts any period of their life with additional wealth coming from accidental bequests. Consider the total amount of wealth saved in the previous period by individuals who are currently deceased. Part of this wealth is distributed to the initial cohort. The remainder is equally distributed as bequests

\footnotetext{
${ }^{12}$ This simplification is borrowed from Nakajima (2010) and relies on houses being perfectly liquid. In the absence of uncertainty, choosing the portfolio composition this period or at the beginning of the following period is equivalent, since no new information arises that could make the decision change (see also Gervais (2002)). With uncertainty, the ex ante and ex post optimal decisions need not be the same. We assume that the portfolio can be costlessly rebalanced and, hence, the ex ante decision is redundant.
} 
amongst the whole population, with the per household amount of bequests being denoted by $\operatorname{tr}$ (before any interest income is added on it). As a result, the total wealth to be distributed between consumption of housing services, non housing goods and wealth carried forward is $(1+r)(x+t r)$.

In what follows, we write the problem of the household recursively, with primes denoting a variable next period. An agent is characterized by the individual set of state variables $s=(i, e, x)$, with $s^{\prime}=\left(i+1, e^{\prime}, x^{\prime}\right)$, where $i$ is the age, $e$ is stochastic productivity and $x$ is total wealth carried forward from the previous period. We assume no aggregate uncertainty and focus on steady states, so all equilibrium prices are treated as constant.

Owning vs Renting. ${ }^{13}$ Households can either own or rent houses but the choice is mutually exclusive. There are two key differences between owning and renting in this model. First, the cost of owning and renting are different. The cost of renting is equal to the rent $q$ which is competitively determined and reflects financial costs $r$ plus depreciation costs $\delta_{d, r}$ as in (1). The cost of owning also reflects financial costs and depreciation. However, the financial cost is only implicit (foregone interest $r$ ) and depreciation can be different $\delta_{d, o}$. If depreciation rates were the same, households would be indifferent between owning and renting. In the data, $\delta_{d, o}<\delta_{d, r}$ which implies a lower cost of owning and gives a motive for owning. We maintain this assumption from here onwards. ${ }^{14}$ Second, rented houses come in all possible sizes, whereas owned houses are restricted to be larger than a minimum size. This assumption, which is standard in the housing literature, is intended to capture the fact that it is possible to find a smaller place to live in as a renter (such as a single room in a shared house). In addition, renters and owners differ with regard to their asset choices. Specifically, renters hold all their wealth $x$ in financial assets and cannot borrow, whereas

\footnotetext{
${ }^{13}$ Our modelling of the housing market and the ownership decision is based on several existing quantitative models of housing e.g. Gervais (2002), Yang (2009), Chambers et al. (2009), Nakajima (2010), Diaz and Luengo-Prado (2010) and Fisher and Gervais (2011).

${ }^{14} \mathrm{An}$ equivalent way of modelling a motive for owning, would be to let $\delta_{d, o}=\delta_{d, r}$ and introduce a preference for owning in the utility. None of the results rely on our choice. Additional discussion is provided in the calibration section.
} 
owners allocate their wealth $x$ between financial assets $a$ and a house $d_{o}$ and can use their house as collateral to borrow. ${ }^{15}$ The budget set for a renter is thus

$$
\begin{aligned}
c+q d_{r}+x^{\prime} & =y+(1+r)(a+t r) \\
x & =a \\
a & \geq 0, c \geq 0 \\
d_{r} & \geq 0
\end{aligned}
$$

and the one of an owner is

$$
\begin{aligned}
c+x^{\prime} & =y+(1+r)(a+t r)+\left(1-\delta_{d, o}\right) d_{o} \\
x & =a+d_{o} \\
a & \geq-(1-\chi) d_{o}, c \geq 0 \\
d_{o} & \geq d_{\text {min }}
\end{aligned}
$$

When $a$ is positive, it should be interpreted as savings. These savings are channeled into one of the productive sectors in the economy and generate a return $r$, which the household takes as given. Note that this is essentially a risk-free bond. Therefore productivity and mortality risk cannot be insured against and financial markets are incomplete. When $a$ is negative, it should be interpreted as a mortgage or home equity loan. In particular, an owner can borrow up to a fraction $(1-\chi)$ of the value of their house. This also means that, when buying a home, a household needs to make a downpayment equal to at least $\chi d_{o}{ }^{16}$

Household Problem. Despite the lower cost of owning, some households become

\footnotetext{
${ }^{15}$ We use $d$ for housing services as well as for the stock of housing assets. The reason is that the production of services out of the asset is assumed to be one-to-one. In addition, we distinguish between owners, $d_{o}$, and renters, $d_{r}$. Although the housing services out of a house of size $d$ are the same whether owned or rented, $d_{o}$ is part of wealth whereas $d_{r}$ is not.

${ }^{16}$ We follow Yang (2009) in assuming this close relationship between downpayment requirements and collateral values. This significantly simplifies the computational problem at hand by reducing downpayment and collateral constraints to a single inequality constraint given in (11).
} 
renters. There are two reasons for this: first, a household might not be able to afford the downpayment required to buy the minimum house $d_{\min }$. Second, a household might prefer to leave in a house smaller than $d_{\min }$ given their wealth level. Households evaluate these trade-offs by solving the following optimization problem:

$$
V(s)=\max \left\{V_{o}(s), V_{r}(s)\right\}
$$

where $V_{o}$ is given by

$$
V_{o}(s)=\max _{\left\{c, d_{o}, a, x^{\prime}\right\}}\left\{u\left(c, d_{o}\right)+\beta \psi_{i} E V\left(s^{\prime}\right)\right\} \text { s.t. }
$$

and $V_{r}$ is given by

$$
V_{r}(s)=\max _{\left\{c, d_{r}, a, x^{\prime}\right\}}\left\{u\left(c, d_{r}\right)+\beta \psi_{i} E V\left(s^{\prime}\right)\right\} \text { s.t. }
$$

$$
(5)-(8)
$$

Recall that the state vector is given by $s=(i, e, x)$ and note that survival probabilities $\psi_{i}$ depend only on age $i$, not on the other elements of $s$.

Equation (13) represents the tenure decision, where $V_{o}$ and $V_{r}$ are the values of owning and renting respectively. The Bellman equation (14) is the problem of a homeowner. A homeowner chooses consumption $c$, financial assets $a$, owned housing assets $d_{o}$ and wealth carried over to the next period $x^{\prime}$. As mentioned earlier, when a household owns housing assets, they cannot rent and $d_{r}=0$. The Bellman equation (15) is the problem of a renter. A renter chooses $c, a, x^{\prime}$ and $d_{r}>0$. Mirroring the owner's problem, $d_{o}=0$ because of the exclusivity assumption.

The solution to the dynamic programming problem above yields optimal decision rules for consumption $g_{c}(s)$, owned houses $g_{d_{o}}(s)$, rented houses $g_{d_{r}}(s)$, financial assets $g_{a}(s)$ and wealth carried forward $g_{x}(s)$. When integrating out the decisions of different agents to obtain 
aggregates, it is helpful to have the housing policy functions defined for every individual. Thus, we define $g_{d_{r}}(s) \equiv 0$ for owners (i.e. for all $s$ s.t. $\left.V_{o}(s) \geq V_{r}(s)\right)$ and $g_{d_{o}}(s) \equiv 0$ for renters (i.e. for all $s$ s.t. $V_{o}(s)<V_{r}(s)$ ).

\subsection{Government}

The government runs a pay-as-you-go social security system in order to provide retirement income. We assume that the retirement system is self-financed. In order to finance retirement benefits, the government collects proportional payroll taxes $\tau_{s}$ from the labor earnings of workers. The social security funds are distributed to all retirees in equal amounts, denoted by $b$.

\section{Recursive Competitive Equilibrium}

In what follows, we define the stationary recursive competitive equilibrium. To do this, let $M$ be the space of individual state variables and let $\mu$ be the probability measure defined over the Borel $\sigma$-algebra generated by $M$. Households perceive that this probability measure evolves according to the law of motion:

$$
\mu^{\prime}=\Gamma(\mu)
$$

Definition. Given an initial distribution of wealth for the entering cohort and given a social security tax rate $\tau_{s}$, a stationary recursive competitive equilibrium consists of a value function $V(s)$, optimal decision rules $\left\{g_{c}(s), g_{d_{o}}(s), g_{d_{r}}(s), g_{a}(s), g_{x}(s)\right\}$, aggregate demand levels for non-housing capital, rental housing capital, skills and raw labor $\left\{K, D_{r}, U, H\right\}$, prices $\left\{r, w_{u}, w_{h}, q\right\}$, transfers $t r$, social security benefits $b$ and a measure $\mu$ such that:

1. Given prices, transfers and benefits, the value function $V(s)$ is the solution to the household's problem defined in $(13)-(15)$ and $g_{c}(s), g_{d_{o}}(s), g_{d_{r}}(s), g_{a}(s)$ and $g_{x}(s)$ are the associated optimal policy functions. 
2. Given prices, the representative firm maximizes profits, leading to the competitive factor prices in (2)-(4).

3. Given prices, the real estate sector maximizes profits, leading to competitive rental prices as in (1)

4. Prices are such that all markets clear. In particular (all the integrals are over $M$ ), the market for raw labor clears

$$
U=\int u d \mu
$$

the market for skills clears

$$
H=\int h d \mu
$$

the financial market clears

$$
K+D_{r}=\int g_{a}(s) d \mu
$$

and the housing rental market clears

$$
D_{r}=\int g_{d_{r}}(s) d \mu
$$

5. The government's social security program is self financed

$$
\tau_{s} \int e\left(w_{u} u+w_{h} h\right) d \mu=\int b d \mu
$$

6. The total amount of accidental bequests is equal to the total amount of transfers plus the total initial wealth of the entering cohort $X_{1}$

$$
\int(1-\psi) g_{x}(s) d \mu=\int \operatorname{tr} d \mu+X_{1}
$$

7. The transition function $\Gamma$ is generated by the optimal decisions for households and by 
the law of motion for the shocks.

In the preceding definition, it is understood that $h, b$ and $\psi$ are all given functions of the state $s$ (note they depend on age $i$ only, they do not depend on productivity $e$ or wealth $x$ ). Using the market clearing conditions, it is easy to show that the aggregate resource constraint of the economy is

$$
C+\delta_{k} K+\delta_{d r} D_{r}+\delta_{d o} D_{o}=Y
$$

where

$$
\begin{aligned}
C & \equiv \int g_{c}(s) d \mu \\
D_{o} & \equiv \int g_{d_{o}}(s) d \mu
\end{aligned}
$$

\section{Quantitative Results}

The theoretical model presented in the two preceding sections has the potential to deliver the qualitative prediction that homeownership rates should fall for younger households and rise for older households as a result of SBTC. In this section we aim to confirm this conjecture and, more importantly, to investigate whether the mechanism proposed is strong enough to explain the magnitude of the changes observed in the data. The first subsection carefully calibrates the economy using aggregate (BEA) data as well as CPS data on wage income and homeownership rates by age. The second subsection discusses the numerical results.

\subsection{Calibration}

In the model, one period represents five years. Age 1 in the model corresponds to the actual age group of 20-24. $I$ is set to 12 , corresponding to the actual age group of 75-79 and $I_{r}$ is set to 9 , implying that agents retire at the actual age group of 65-69. We allow for population growth over time. We set the annual population growth rate to $1.2 \%$, which 
corresponds to the average annual population growth rate in the US over the last 50 years. The survival probabilities $\psi_{i}$ are constructed from the Life Tables of the Social Security Administration for the years 1977 and 1997.

The social security tax is set to $\tau_{s}=5.4 \%$ to match a replacement ratio of $33 \%$ over average wage income following Nakajima (2010). Initial assets for the new entrants, $X_{1}$, are assumed to be distributed uniformly with an upper bound of $\bar{X}{ }^{17}$ This upper bound, together with the minimum size of housing $d_{\min }$ are chosen jointly to match an initial aggregate homeownership rate of approximately $64 \%$ and an initial homeownership rate of $24 \%$ for the 20-24 year old. As for the downpayment fraction $\chi$, we follow the literature on housing in assuming that $\chi=0.2$. This also implies that a homeowner can borrow up to $80 \%$ of the value of their house.

Regarding preferences, the instantaneous utility function takes the following form

$$
u(c, d)=\frac{\left(c^{\lambda} d^{1-\lambda}\right)^{1-\sigma}}{1-\sigma}
$$

with a risk aversion parameter $\sigma$ equal to 2 .

The parameters $\delta_{d, r}, \delta_{d, o}, \delta_{k}, \beta, \lambda$ and $\alpha$ are calibrated to match long run ratios computed from NIPA and Fixed Asset Tables data. In mapping our model to data, we identify nonhousing capital $K$ with non-residential fixed assets, inventories and consumer durables and housing capital $D_{o}+D_{r}$ with residential fixed assets. A similar distinction is drawn between housing investment $I_{d}$ and non-housing investment $I_{k}$. In addition, we separate housing services out of production $Y .{ }^{18}$ The values for $\delta_{k}, \beta, \lambda$ and $\alpha$ are chosen to ensure that our economy before SBTC conforms to the following ratios, $\frac{I_{k}}{Y}=0.19, \frac{K}{Y}=1.65$ and $\frac{D_{0}+D_{r}}{Y}=1.08$, as well as to a capital income share of $\frac{\left(r+\delta_{k}\right) K}{Y}=0.32$. Two additional pieces of information are needed to pin down $\delta_{d, r}$ and $\delta_{d, o}$. We match $\frac{I_{d}}{Y}=0.047$, which pins down

\footnotetext{
${ }^{17}$ The assumption of a uniform initial asset distribution is not critical for the results. We have also solved the model with a normal and a lognormal distribution for initial assets and our results are unaffected.

${ }^{18}$ More details are provided in Appendix B.
} 
the overall amount of depreciation of houses. For the relative size between the depreciation rate of owned and rented houses, we look directly to the data. We use the Fixed Asset Tables from the $\mathrm{BEA}^{19}$ and find that the implied depreciation rate of rented houses in the data is $15 \%$ larger than the one for owned houses. This relative size governs the difference between the cost of renting and the cost of owning in the model. Although we need this difference to be strictly positive in order to generate a motive of owning, the exact size of this difference is not crucial for our quantitative results. The reason is that we target ownership rates for the young and in the aggregate in the economy before SBTC by calibrating other parameters, namely $d_{\min }$ and $\bar{X}$.

Table 2 summarizes the parameter values and the associated targets. Although each parameter is closely associated to one target, matching all targets in practice requires joint (numerical) calibration. The value of $\lambda=0.853$ that achieves the intended calibration also implies a ratio of non-housing consumption over total consumption expenditures which is roughly in line with the one in the data. The TFP parameter $A$ is normalized to 1.

We now turn to the parameters governing the labor income process that households are facing. These include the endowments of raw labor $u$ and skills over the life cycle $\left\{h_{i}\right\}_{i=1}^{9}$, the technology parameter $\gamma$ which governs the skill premium and the stochastic process for the idiosyncratic productivity shocks. We first discuss the deterministic components and then move to the stochastic one.

We use the March Supplement of the CPS dataset to calibrate the deterministic component of labor income. We compute deterministic earnings profiles for both the 1970s and the 1990s closely following the method used by Heathcote et al. (2010). Specifically, we first construct hourly earnings data following the same procedure but focusing on ages 20-65 and restricting the sample to full time working, male household heads. ${ }^{20}$ Subsequently, we follow

\footnotetext{
${ }^{19}$ Specifically, Fixed Asset Tables 5.1 and 5.4, which contain Current-Cost Stock Net Stock and Depreciation of Residential Fixed Assets by Type of Owner, Legal Form or Organization and Tenure Group.

${ }^{20} \mathrm{~A}$ similar picture and similar results emerge if we use the full sample, which includes females and part time workers.
} 
Hansen's (1993) procedure to obtain productivity profiles by age for each year, by dividing the average hourly earnings for each age by the average hourly earnings over all ages. We average over all years between 1970 and 1979 to produce the 70's profile and over all years between 1990 and 1999 to produce the 90's profile. The profiles for the two periods resulting from a fitted quadratic polynomial for each profile are depicted in Figure $4 .{ }^{21}$ We calibrate the evolution of human capital stock over the life cycle $h_{i}$ to match exactly the 70's profile.

Our life cycle profiles are based on cross sections of individuals instead of a panel. The reason for this is that the cohorts entering labor markets in the 90s are still in the middle of their life-cycle, so we cannot have panel data information for their full life-cycle profile. Kambourov and Manovskii (2009) point out that age-profiles of earnings could appear steepening in a cross-section, but actually be flattening over the life-cycle. Using data up to 1997 and including all cohorts that entered the labor market between 1949 and 1990, they find profiles have flattened. We repeat their exercise focusing on the years and cohorts relevant for our paper. Specifically, we extend our sample back to 1967 and up to 2009 and focus on cohorts entering between the end of the 60s all the way up to the end of the $90 \mathrm{~s}$. We find that life cycle profiles have steepened for those cohorts. ${ }^{22}$

As Figure 4 illustrates, there has been an increase in the experience premium during the period of study. A more complete picture of the changes in experience premia for the period 1968-2006 is displayed in Figure 5, which essentially reproduces the following qualitative finding of Heathcote et al. (2010). The experience premium, defined as the relative earnings of the 45-55 year old age group to the 25-35 year old age group, increased between 1977 and 1997, but seems to have stabilized towards the end of the sample period. A similar picture emerges from Figure 6, which depicts the relative earnings at age $45-50$ to age 20-25. In the 1990s, this alternative definition of the experience premium corresponds to the ratio of the maximum to minimum income. We find that targeting this predicts income profiles that

\footnotetext{
${ }^{21}$ More details about the data are provided in Appendix A.

${ }^{22}$ More details about this exercise and why it gives different results than Kambourov and Manovskii (2009) are provided in Appendix A. We thank the authors for providing their codes.
} 
are closer to the data and we will therefore use this alternative definition of the experience premium throughout the paper.

Our experiment will consist in changing the value of $\gamma$ so as to capture this increase in experience premia. Since we have calibrated the benchmark economy to match the whole life cycle profile of earnings, the experience premium in that economy matches that of the data. In contrast, the life cycle profile for earnings in the 1990s as well as the experience premium after SBTC are generated endogenously by the model, given the stocks of raw labor and human capital.

The relative price of skill in the model is equal to $\frac{w_{h}}{w_{u}}=\frac{1-\gamma}{\gamma}$. We use the change in $\gamma$ to capture SBTC. For the benchmark economy representing the 70s, the values of $\gamma$ and $u$ are simply normalizations. We normalize $\gamma=0.5$ before SBTC and choose $\gamma$ after SBTC to match the ratio of maximum to minimum wage in the $90 \mathrm{~s}$. This is calculated from the observed productivity profiles, assuming cohort sizes consistent with our model. Although the value of raw labor $u$ does not affect any steady state variable before the SBTC, its value does matter for the precise effects of a change in $\gamma$, i.e. after SBTC, and particularly for its effect on average income levels. Household income, as opposed to individual income, has increased due to increased female hours worked and female labor force participation. We follow the back of the envelope calculation used by Fisher and Gervais (2011) to specify the effect of those changes on household income, which is found to be a $4.4 \%$ increase. We choose $u$ so that the average household income level in the new steady state is $4.4 \%$ larger than in the old steady state.

In addition to the deterministic life cycle changes, there is also a stochastic component to earnings. The process is calibrated following Storesletten, Telmer and Yaron (2004). The authors estimate an $\operatorname{ARMA}(1,1)$ process, obtaining an autocorrelation of $\rho=0.95$, a standard deviation of 0.25 for the transitory innovation and a standard deviation of 0.17 for the innovation of the persistent $\operatorname{AR}(1)$ component. We discretize the $\operatorname{AR}(1)$ component into a five state Markov chain following Tauchen and Hussey (1991). The resulting shock values 
are normalized so that their mean equals one.

\subsection{Results}

\subsubsection{Before $S B T C$}

We begin with a brief discussion of the economy before SBTC. The life cycle profile of income for the 1970s shown in Figure 7 is calibrated to match exactly the one in the data. The endogenously arising life cycle profile of wealth for the average household is shown in Figure 8. Note that the entering cohort receives some assets as bequests, implying that the average young household has positive wealth which is decumulated in the first period. Subsequently, the average household starts accumulating wealth and continues to do so until the age of retirement. During retirement, the accumulated wealth is used to supplement retirement benefits coming from social security. Figure 8 also presents a decomposition of wealth into financial assets and houses. The profile for houses is much smoother due to the dual role of houses as saving instruments as well as housing services. The consumption smoothing motive dictates that housing services are smoothed over the life cycle. As a result, the variability of overall wealth is mainly picked up by financial asset holdings. Matching observed asset accumulation patterns in the data is not the objective of our paper, this task has been undertaken by Fan Yang (2009). However, we note that some important features of the data reported in Yang (2009) are replicated by our model, namely the smoothness of the housing asset profile relative to financial assets and the fact that the housing asset profile is initially rising but eventually flattening out. In addition, combined financial wealth for owners and renters at the peak of the profile is about 4 times as high as housing wealth. This seems roughly in line with the numbers reported in Figure 5 of Yang (2009)'s article. The main deviation from the empirically observed patterns comes after retirement. Yang (2009) explains how adjustment costs are crucial in maintaining a flat housing asset profile 
even after retirement and this channel is missing from our model. ${ }^{23}$ In addition, in both Yang (2009) and our paper, the models predict a fast decumulation of financial assets after retirement, a feature that is common in models with a finite lifetime horizon.

Figure 9 and Table 3 show the resulting profile of homeownership by age for the 1970s (Ante). The entering cohort has a homeownership rate of $23.6 \%$ which matches the one in the data by virtue of our calibration. Subsequently, homeownership rates increase until they reach a peak in retirement and then decrease slightly in the last period of life. The profile follows closely the one from the data shown in Figure 2 and Table 3. Table 4 provides a closer look at the model results by age groups and compares to the data. The model predicted homeownership rate for the 20-44 age group is 48\%, which is slightly lower than the $54 \%$ observed in the data. The homeownership rate for the $45-59$ age group is $80 \%$ in the model, which matches closely what is observed in the data, $79.5 \%$. The homeownership rate for the 60-79 age group is $85 \%$ in the model, which is higher than the one in the data, $75 \% .{ }^{24}$ The main divergence occurs for retired households, for whom we observe an earlier and stronger decrease in ownership rates in the data.

In our model, the cost of owning is less than the cost of renting due to a lower depreciation rate. In the absence of any frictions, all households would therefore choose to own. However, there are two reasons why some households end up becoming renters: the minimum (owned) house restriction and the downpayment requirement. A household is constrained in the minimum house if its desired house size is smaller than the minimum house. A household is constrained in the downpayment constraint if the assets it enters the period with are not enough for a downpayment for their desired house. A household's desired house size is the house size it would choose if the two restrictions where lifted and the household could own

\footnotetext{
${ }^{23}$ Adding adjustment costs would significantly increase the computational burden involved, particularly since we are using a very fine grid on houses in order to avoid our results depending on the grid choice.

${ }^{24}$ There is some degree of freedom about how to group households. We choose to distinguish the three groups by looking at the data. The first group is the one that experienced a significant decrease in homeownership rates, the second is the one where there was little change and the third is the one that experienced a significant increase. In aggregating across ages, we use the model's cohort sizes for both the model and the data.
} 
their desired house regardless of the house size or their asset levels. It follows from the preceding discussion that all unconstrained households are owners. However, this does not imply that all owners are unconstrained. First, some owners would prefer to own a larger house, but do not have sufficient savings for a downpayment of such a large house. So, they end up buying a house that is smaller than their desired house. Second, some owners are constrained by the minimum house restriction in the following sense. They would prefer to live in a smaller house, but the advantages of ownership induce them to buy a larger house to overcome the minimum house constraint.

Frictions in the housing and financial markets distort the housing consumption behavior of agents. The effects of those frictions are different depending on households' characteristics. The minimum house constraint is relevant for households with low desired consumption levels. Hence, it is more binding the lower the income (which depends on age and productivity) and the lower the wealth. Given a substantial amount of heterogeneity in productivity conditional on age, this constraint can be binding for both young and old households. In contrast, the downpayment constraint is relevant for households with low asset holdings, but potentially high and rising income. These are typically younger households who would prefer to live in a bigger house, considering their positive income prospects, but low asset holdings prevent them from doing so. The downpayment constraint is irrelevant for older households (above 50) since those have accumulated enough assets. Accordingly, older households become renters only when their desired house falls below the minimum house size available for owning.

\subsubsection{After $S B T C$}

The economy after SBTC differs to the one before SBTC in two important ways. First, the experience premium is higher because of SBTC (modelled as a smaller $\gamma$ ). Second, mortality rates are lower to conform with the data in the 90s. SBTC implies that the relative price of skill is now higher and this has a direct impact on the life cycle profile of earnings, as 
shown in Figure 7. Younger households, who have relatively low skill levels, experience an income decrease and middle to old age households experience an income increase. To put it succinctly, the income profile steepens.

Facing the new income profile, the average household changes its consumption and savings decisions. Figures 10, 11 and 12 illustrate the effects of SBTC on the life cycle profile of wealth and its decomposition into financial assets and houses. Lower income at the early stages of the life cycle and higher expected income growth lead the average young household to accumulate less wealth, due to the fact that markets are incomplete. As the household gets older, income grows with experience and eventually surpasses the income at older ages before SBTC thanks to the higher experience premium. Because lifetime household income also increases, the peak of the wealth profile is now higher. This adjustment is reflected in both financial and housing assets. To summarize, compared to the economy before SBTC, households have less wealth when young and more wealth when old. As can be seen in Figure 9 and Table 3 , this change directly translates to a steeper homeownership profile.

Recall that the downpayment constraint is especially relevant for younger households who have not had the opportunity to accumulate savings. The fact that younger households have less wealth after SBTC is one of the driving factors for their decreased homeownership rates. The minimum housing constraint is also more binding due to the steeper consumption profiles generated by SBTC in the presence of incomplete markets. On the other hand, older households become renters only when their desired house falls below the minimum house available for owning. Since the wealth level at older ages is a better indicator for the consumption level, the fact that older households have more wealth after SBTC directly translates to an increase in homeownership rates for older households. In other words, with higher wealth, there are now more older households who want to live in a large enough house.

Qualitatively, our model is fairly successful in matching the data in the following sense: we find a decrease in homeownership rates for households who are less than 45 years old as well as an increase in rates for households who are more than 50 years old. This is exactly 
what we observe in the data. In other words, the model is able to generate the crossing of homeownership profiles that we see in the data. The model is also able to match the fact that the decrease in homeownership rates is more significant the younger is the cohort. Similarly, the increase in homeownership rates is higher the older is the cohort.

The model is also successful from a quantitative perspective. First, consider aggregate homeownership. In the data, this is relatively stable, exhibiting a slight decrease of 1.4 percentage points between the 1970s and the 1990s. Our model also produces a small decrease in aggregate homeownership of around 2.4 percentage points. Our main interest, however, is in the age composition. Table 3 reports the change in ownership rates by age for the model and for the data. Although the changes do not exactly match those in the data for every age, the order of magnitude seems to be very similar. The decrease for young households produced by the model seems to be roughly in line with the one in the data. For older households, the model under predicts the increase in homeownership rates.

Table 4 provides an attempt at obtaining an overall, quantitative measure of the success of the model by looking at the homeownership changes for young, middle-aged and old households. To construct these three groups, we put together households 20-44 years old (young), households 45-59 years old (middle-aged) and households 60-79 years old (old). For the young group, homeownership rates have fallen by 7.1 percentage points in the data. The model predicts a decrease of 6.8 percentage points. According to this measure, the model can explain $96 \%$ of the decrease in young homeownership. Homeownership rates were relatively stable for the middle-aged group, a feature also captured by our model. For the old group, homeownership rates increased by 7.9 percentage points in the data, while the model predicts an increase of 3.4 percentage points, i.e. it explains $42 \%$ of the increase for the old. Our model clearly misses some important aspect of homeownership decisions for this last group. As noted by Fisher and Gervais (2011), an obvious candidate is the history of this group's life-cycle before the 70s. Particularly striking is the low level of ownership rates for this group in the $70 \mathrm{~s}$. We conjecture that this is related to the levels of wealth 
accumulated by this group prior to 1970. Our model abstracts from such considerations, so it cannot fully explain the observed increases for the old. It does, however, provide an additional mechanism leading to such an increase. Quantitatively, this mechanism is found to be non-trivial.

To sum up, the model is able to generate the same qualitative behavior as in the data and to account for a significant fraction of the quantitative changes observed for younger households. We conclude that SBTC was an important factor contributing towards the changes in the homeownership distribution between the 1970s and the 1990s.

\subsubsection{The Effect of Lower Mortality Rates}

In our main experiment, we have assumed that SBTC occurs at the same time as mortality rates fall (as they did during the period of interest). To investigate on the importance of the two mechanisms, we have also considered a calibration where mortality rates are kept fixed. In that case, we have recalibrated the value of $u$ in order to obtain the same $4.4 . \%$ increase in the average household's income as in our benchmark experiment. ${ }^{25}$

The main qualitative conclusion, that life cycle profiles of homeownership steepen as a result of SBTC, remains true when we ignore changes in mortality. However, without the mortality change, aggregate homeownership decreases more strongly as a result of SBTC. In other words, the aggregate homeownership rate is higher in our preferred economy which includes the mortality changes ( $61.4 \%$ vs $59.4 \%$ ). This is mainly due to a composition effect. Higher mortality rates imply relatively more older households in the economy and those households have higher ownership rates. Thus, mortality helps the model to match the small decrease in aggregate homeownership that is observed in the data.

The effects of mortality on the life cycle profile of ownership are much less significant, as can be seen in Figure 13. Compared to the version that keeps mortality rates fixed, our preferred calibration produces virtually identical ownership rates for most ages and only

\footnotetext{
${ }^{25}$ Note that this has no effect on the ante economy, $u$ is simply a normalization for that economy. Hence, in what follows we compare the economy after SBTC with and without the mortality change.
} 
slightly higher ownership rates for the young. Part of the effect of mortality on the life cycle profile of ownership is through the following general equilibrium effect on interest rates. Higher survival rates, imply more older households which, in turn, implies higher aggregate wealth held. In equilibrium, the interest rate adjusts downwards, so that the economy with no mortality change has a higher interest rate than the one with mortality changes. Considering a household's Euler equation, consumption growth over the life cycle will be determined by the product of the interest rate $(1+r)$, the discount factor $\beta$ and the survival rates $\psi_{i}$. Taking mortality rate changes into account implies lower interest rates and higher survival rates. Thus, the two effects cancel each other to a large extent. This is true especially for older households who experienced significant increases in survival rates in the data. For younger households, survival rates were virtually unchanged, so the interest rate effect dominates. This produces flatter consumption profiles and therefore mitigates the decrease in ownership of the young resulting from SBTC. This brings the model results slightly closer to the data for the young.

Overall, we conclude that the steepening of age profiles of ownership is largely due to SBTC and the main effect of mortality is to bring its effects on aggregate ownership more in line with the data.

\subsubsection{General Equilibrium Effects}

Our model is a general equilibrium (GE) model where the interest rate $r$ and the wages $w_{u}$, $w_{h}$ respond to changes in the capital-output ratio according to (2) - (4). In our benchmark experiment, the capital-output ratio falls slightly and this leads to an increase in $r$ and a (ceteris-paribus) decrease in $w_{u}, w_{h}$. Here, we investigate on the importance of this general equilibrium channel for the results reported. We do this by considering a partial equilibrium (PE) version of our model, where the interest rate is kept fixed and the effects of the capitaloutput ratio on $w_{u}$ and $w_{h}$ are shut down. We recalibrate $\gamma$ and $u$ in order to match the same experience premium and average wage increase as in the GE version of the economy. 
The results of this experiment are depicted in Figure 14 and Table 5.

The homeownership profiles by age become steeper in both the GE and PE versions of the model. However, this effect is more pronounced in the GE version, illustrating that the GE price effects are not trivial. The difference is due to the different interest rate. Whereas in GE, interest rates increase, in $\mathrm{PE}$ the interest rate is fixed exogenously. The higher interest rate in the GE economy induces households to save more earlier in life and leads to steeper consumption profiles. In turn, this directly translates into steeper homeownership profiles. The end result is that the GE version of the model performs better in capturing a higher percentage of the decrease in homeownership of the young. We conclude that general equilibrium effects improve the quantitative match of our model with the data.

\section{Conclusion}

This paper studies the relationship between the observed changes in the US homeownership distribution over the period 1970s-1990s and the SBTC that occurred during the same period. We argue that the increase in the returns to skills associated with SBTC implies a steeper profile of earnings by age which, in turn, leads to steeper profiles of homeownership by age. We explain how this arises from a simple consumption smoothing motive which leads to a slower accumulation of savings at the early stages of the life cycle. In the absence of complete financial markets, and given the requirement of a substantial down payment when buying a house, this leads younger households to delay their decision to buy a house. Older households, possessing more experience/skills, benefit from the increased returns to skills and their increased income could potentially lead to higher investment in homes.

To analyze the validity of these conjectures and to obtain a measure of their quantitative importance, we have constructed a model with housing and skill accumulation and have calibrated it to the US economy. Qualitatively, the model is able to generate the changes in the age distribution of homeownership while, at the same time, leaving aggregate homeownership roughly constant and in line with the data. Quantitatively, SBTC emerges as a 
significant contributing factor to the decline in homeownership for the young, accounting for a large fraction of this decline. It is also predicted to contribute to the increase in homeownership for the old. Fully understanding the homeownership choices of older generations would require modelling important aspects that we have abstracted from, such as annuity markets, bequest motives and medical expenses.

Another aspect that we have not modelled explicitly is the endogenous decision to accumulate human capital. We conjecture that modelling on-the-job training would lead to similar results to the ones obtained in the present setting. If human capital could be accumulated endogenously, the rise in the return to skill would increase accumulation incentives at a younger age. In turn, this would lead to a decline in labor income early in life. At the same time, the additional human capital accumulated would pay off later in life through higher wages. Thus, allowing for endogenous human capital accumulation provides an endogenous amplification mechanism for the effects of SBTC on earnings profiles. In such an extension, our calibration would have to be adjusted since a smaller exogenous change in the parameter controlling SBTC would be needed to match the observed rise in experience premia. Given the same level of steepening for earnings profiles by age as in the data, the effect on age-profiles of homeownership should, in principle, remain similar in magnitude to the one we find.

Endogenous human capital accumulation could perhaps provide new insights on the reasons underlying the aggregate homeownership boom after the period we study (i.e. after 1995). While it is well established that part of this boom was due to mortgage innovations, it is possible that some of the increase is also related to the slowdown in SBTC that occurred after 1995. To the extent that new entrants in the labor market foresaw the slowdown, their incentives to acquire skills were diminished. Following the logic of our paper, this should imply faster accumulation of wealth and, as a result, more available savings to be used as downpayment. In turn, this should lead to increases in homeownership rates for young households, which were indeed the age group driving aggregate ownership rates upwards. 
Our model suggests that wealth and portfolio decisions by households were significantly affected by skill-biased technological change. The present paper investigates the effects of SBTC on the decision to own homes. Steeper income profiles by age generated by these labor market changes could have also affected other dimensions of households' portfolio choices. In particular, it is likely that these changes resulted in higher levels of household debt, contributing to the surge in consumer debt (and bankruptcy) that was observed during the period of study. 


\section{Appendix A: CPS Data Appendix}

We use the March CPS survey data for the period 1970 to 1999 to construct both the earnings profiles and the homeownership-by-age profiles. In this section we describe the construction of these profiles in more detail.

\section{Earnings Profiles and Experience Premium}

To calculate the earnings experience premium and the earnings profiles, we first construct annual earnings and hourly earnings following an almost identical procedure to the one used by Heathcote et al (2010). In terms of cleaning the data, their approach is intended to clean miscoded or apparently miscoded observations. Thus, they clean households with no (or more than one) reference person and households with any members that are assigned negative weights or that report positive earnings but zero weeks worked or that report less than half the minimum wage earned or that report less than 260 hours per year. We do the same but also restrict our sample to full time male heads of household. The only additional cleaning they do is in focusing on ages 25 to 60 . In order to capture the entire working life cycle we instead focus on ages 20-65. This leaves us with 30 years of data on individuals by age.

To calculate annual earnings and hourly earnings, we follow their approach in defining annual earnings as labor income plus two thirds of self employment income and construct hourly earnings by dividing annual earnings by annual hours worked. We also deal with topcoded observations in a manner very similar to their approach. Before 1995, for each type of income, we fit a Pareto density to the top $10 \%$ of non-topcoded observations and use extrapolation to forecast the mean value for the top coded observations. All top coded observations are then replaced by that extrapolated mean value. After 1995, the CPS actually

reports mean values for topcoded observations so we use directly those. ${ }^{26}$ The resulting hourly earnings are averaged for every year and every age using individual weights.

\footnotetext{
${ }^{26}$ Here, we differ from Heathcote et al. (2010), who use the extrapolation procedure also for the years after 1995. They do not report significant differences from doing so.
} 
After constructing the hourly earnings, we follow Hansen's (1993) procedure to obtain life cycle productivity profiles for each year. In particular, for a given year, we divide the average hourly earnings for each age by the average hourly earnings over all ages. This leaves us with 30 age-profiles of productivity, one for each year from 1970 up to 1999. Finally, we average over all years between 1970 and 1979 to produce the "70's" profile and over all years between 1990 and 1999 to produce the "90's" profile.

Our productivity profiles are based on cross sections of individuals. From a theoretical point of view, given our focus on steady states, cross-sectional and cohort analysis is the same. Of course, this need not be true from a data point of view. Unfortunately, individuals that entered the labor market in the 1990s are still in the middle of their life-cycle, so we lack information for their full life-cycle earnings profiles. This is why we use cross-sectional profiles. It is important, however, to use what information is available to determine whether the steepening of profiles is still true from a cohort perspective. Although the CPS does not contain enough information to do this on a panel, we can still track the average hourly earnings of different cohorts over time. For this analysis, we actually extend our sample back to 1967 and up to 2009, so that we have as much information about the early and late cohorts as possible. The resulting productivity profiles obtained for the cohorts of the $70 \mathrm{~s}$ and the 90s are depicted in Figure 15.

At a first glance, profiles appear to have steepened, even when looking at cohorts. A more careful look at the data confirms this. We follow the procedure in Kambourov and Manovskii (2009), who use CPS data in exactly the same way to estimate the following regression

$$
w_{i t}=\beta_{0}+\beta_{1} z_{i}+\beta_{2} z_{i}^{2}+\beta_{3} z_{i} x_{i t}+\beta_{4} x_{i t}+\beta_{5} x_{i t}^{2}+\beta_{6} x_{i t}^{3}+\varepsilon_{i t}
$$

where $z_{i}$ is the cohort entry year and $x_{i t}$ is the age of the cohort at time $t$. A positive coefficient $\beta_{3}$ on the interaction term is interpreted as evidence of steepening. We indeed obtain 
a positive and significant coefficient. ${ }^{27}$ This is in contrast to Kambourov and Manovskii (2009)'s result who report a flattening of life cycle profiles. There are several reasons why our result is different than theirs. First, we include more recent data (they use data up to 1997) which allows the life cycle profile of those in the 1990's to be better captured. As discussed in Guvenen and Kuruscu (2009), it could be that life cycle profiles are flatter in the beginning of the life cycle and then turn sharply steeper later on. In this case, missing the latter part of the profile tends to bias the result towards finding a flattening. Second, perhaps more importantly, the approach of Kambourov and Manovskii (2009) bunches together different cohorts, starting as early as 1949 and going all the way to 1990. When one averages over all those cohorts, one finds earnings profiles have flattened over time but this is consistent with steeper profiles for the 90s cohorts compared to the 70s. All that is needed is sufficient flattening from the 50s to the 70s. This is compounded by the lack of significant amounts of data for the 90s cohorts (when only data up to 1997 is used) which are the ones that actually face steeper profiles.

\section{Homeownership Profiles}

We use the same CPS data to obtain homeownership rates by age and we include ages 20 to 79 . Since we ignore the data for years 1979 to 1982 and homeownership is reported in the CPS only starting in 1976, we are left with three years of homeownership data in the 70s (1976-1978). We use an average over these three years to represent the age-profile of homeownership for the 1970s. Similarly, we use an average for years 1994-1997 for the homeownership profile after SBTC. We consider different age groups and report the homeownership for each group before and after in Figure 2 and Table 3. Our rates are closely in line with those reported by Fisher and Gervais (2011) and by Segal and Sullivan (1998). In addition, aggregate homeownership exhibits the same level of stability close to $64 \%$ that is reported in Garriga et al. (2009).

\footnotetext{
${ }^{27}$ Results are available upon request.
} 


\section{Appendix B: NIPA Data Appendix}

The parameters $\beta, \lambda, \delta^{k}, \delta_{d, o}, \delta_{d, r}$ and $\alpha$ are calibrated to match long run ratios computed from NIPA data as well as the relative size of depreciation rates for rented and owned houses that we observe in the BEA Fixed Asset Tables. Specifically, we ensure that our economy before skill biased technological change conforms to the following (annual) numbers $\frac{K}{Y}=1.65$, $\frac{D_{o}+D_{r}}{Y}=1.08, \frac{I_{k}}{Y}=0.19, \frac{I_{d}}{Y}=0.047, \frac{\delta_{d, r}}{\delta_{d, o}}=1.15$ and capital income share of 0.32 . Here we describe the construction of these ratios.

To construct these ratios, we look at averages for the years 1947 to 2008. The capital stock $K$ includes private non-residential fixed assets, the stock of inventories and the stock of consumer durables. Accordingly, $I_{k}$ includes private non-residential investment, changes in inventories, consumer durable spending and net exports. On the housing side, the housing stock $D_{o}+D_{r}$ is defined as private residential fixed assets and $I_{d}$ as private residential investment. ${ }^{28}$ Our definition of $Y$ in the above ratios captures GDP produced in the nonhousing sector. To construct $Y$, we subtract expenditures on housing services from GDP. ${ }^{29}$ Given our treatment of consumer durables as capital stock, we also need to add the flow of services from consumer durables to our measure of $Y$. These flows are imputed in a manner identical to Cooley and Prescott (1995), which we explain in what follows.

For the computation of the capital share in the production function of the non-housing sector, we follow Cooley and Prescott's (1995) approach closely. In particular, we first look at GDP minus the housing services (HS). Using Gross Domestic Income Table 1.10, we define Labor Income (LI) to be compensation of employees, Unambiguous Capital Income (UCI) to be rental income, corporate profits, interest and business current transfers and Ambiguous Capital Income to include all the rest (i.e. proprietor's income, taxes on production and imports less subsidies and the current surplus of government enterprises). We assume

\footnotetext{
${ }^{28}$ Stock variables are constructed using Table 1.1. Current Cost Net Stock of Fixed Assets and Consumer Durable Goods and Private Inventories Tables 5.7.5A and 5.7.5B. Investment variables are constructed using GDP Table 1.5.5.

${ }^{29}$ These are taken from Table 2.4.5 Personal Consumption Expenditures by Type of Product.
} 
housing income is all unambiguously capital income. We also define depreciation (DEP) to be the consumption of fixed capital. A preliminary share of capital income in private income excluding housing $\theta_{p}$ can then be calculated as

$$
\theta_{p}=\frac{U C I-H S+D E P}{G D P-H S-A C I}
$$

Using this share we calculate capital income in measured GDP excluding housing as $\theta_{p}(G D P-$ $H S)$ and use this to impute the return to capital as

$$
i=\left(\theta_{p}(G D P-H S)-D E P\right) / K
$$

For the years in question this yields an average return of $7.9 \%$. We then look at consumer durables and estimate their depreciation rate by computing the investment to stock ratio and subtracting the growth rate of real GDP (an average of 3.3\%). The average is approximately $23 \%$. The return $i$ and the individual depreciation rates are then used to impute the value of service flows from consumer durables.

The imputed flow is added to our measure of $Y$. The capital share is then recomputed by adding this flow to capital income and to GDP excluding housing, which yields a share $\alpha=0.32$. This share is lower than the Cooley Prescott calculation (0.4) because we do not include government capital in calculations and because we look at shares in non-housing GDP. Given that we do not explicitly model a government, we have to choose how to deal with the government sector in the data. In our model, it is important to capture the relative sizes of housing and non-housing capital for the private sector, since the latter is used as downpayment for the former and the strength of the downpayment constraint depends on the relative sizes of the two. In this sense, it would be misleading if we were to include government capital as part of private capital. Our treatment implicitly assigns all government expenditures (consumption and investment) to private consumption. An alternative 
approach would be to only focus on private GDP and completely exclude the government sector from our calculations. ${ }^{30}$ Following this approach, and assuming that capital and labor shares are the same in the government and in the private sector, has a negligible effect on our calibrated parameters.

\footnotetext{
${ }^{30}$ Pedro Silos (2007) takes this approach.
} 


\section{References}

Aghion, P., Howitt, P., Violante, G.L., 2002. General Purpose Technology and Within-Group Wage Inequality. Journal of Economic Growth 7, 315-345.

Chambers, M., Garriga, C., Schlagenhauf, D., 2009. Accounting for Changes in the Homeownership Rate. International Economic Review, 50 (3), 677-726.

Chambers, M., Garriga, C., Schlagenhauf, D., 2011. Did Housing Policies Cause the PostWar Boom in Homeownership? A General Equilibrium Analysis. Working Paper No. 2011-01, Towson University, Maryland.

Cooley, T., Prescott, E., 1995. Economic Growth and Business Cycles. Frontiers of Business Cycle Research, Princeton University Press.

Díaz, A., Luengo-Prado, M.J., 2010. The Wealth Distribution with Durable Goods. International Economic Review, 51, 143-170.

Fisher, J., Gervais, M., 2011. Why Has Homeownership Fallen Among the Young? International Economic Review, 52 (3), 883-912.

Garriga, C., Gavin, W. T., Schlagenhauf, D., 2006. Recent Trends in Homeownership. Federal Reserve Bank of St. Louis Review, 88(5), 397-411.

Gervais, M., 2002. Housing taxation and capital accumulation. Journal of Monetary Economics, 49, 1461-1489

Guvenen, F., Kuruscu, B., 2009. A Quantitative Analysis of the Evolution of the U.S. Wage Distribution: 1970-2000. NBER Macro Annual, 24, 231-276.

Guvenen, F., Kuruscu, B., 2012. Understanding the Evolution of the U.S. Wage Distribution: A Theoretical Analysis. Journal of European Economic Association, 10 (3), 482-517. 
Hansen, G., 1993. The Cyclical and Secular Behavior of the Labor Input: Comparing Efficiency Units and Hours Worked. Journal of Applied Econometrics 8, 71-80.

Heathcote, J., Perri, F., Violante, G., 2010. Unequal We Stand: An Empirical Analysis of Economic Inequality in the United States, 1967-2006. Review of Economic Dynamics, $13 / 1,15-51$

Hornstein, A., Krusell, P., Violante, G., 2004. The Effects of Technical Change on Labor Market Inequalities. Handbook of Economic Growth, ed. by. Aghion and Durlauf, Elsevier.

Kambourov, G., Manovskii, I., 2009. Accounting for the Changing Life-Cycle Profile of Earnings, Working Paper.

Katz, L. F., Autor, D. H. 1999. Changes in Wage Structure and Earnings Inequality. Handbook of Labor Economics, ed. by O. C. Ashtenfelter, and D. Card, 3A, 1463-1555. Amsterdam: North-Holland.

Krusell, P., Ohanian, L., Rios-Rull, J., Violante, G., 2000), Capital-Skill Complementarity and Inequality: A Macroeconomic Analysis. Econometrica 68, 1029-1054.

Li, W., 2005. Moving Up: Trends in Homeownership and Mortgage Indebtedness. Federal Reserve Bank of Philadelphia, Business Review, Q1, 26-34.

Jeong, H., Kim, Y., Manovskii, I., 2010. The Price of Experience. Working paper.

Nakajima, M., 2010. Optimal Capital Income Taxation with Housing. Working paper.

Segal, L., Sullivan, D. G., 1998. Trends in Homeownership: Race, Demographics, and Income. Economic Perspectives, 22.

Silos, P., 2007. Housing, Portfolio Choice and the Macroeconomy. Journal of Economic Dynamics and Control 31, 2774-2801. 
Storesletten, K., Telmer, C.,Yaron, A. 2004. Cyclical Dynamics in Idiosyncratic LaborMarket Risk. Journal of Political Economy, 112 (3), 695-717.

Tauchen, G., Hussey, R., 1991. Quadrature-Based Methods for Obtaining Approximate Solutions to Nonlinear Asset Pricing Models. Econometrica 59 (2), 371-96.

Violante, G.,2002. "Technological Acceleration, Skill Transferability and the Rise in Residual Inequality". Quarterly Journal of Economics 117, 297-338.

Weinberg, B.A., 2005. Experience and Technology Adoption. IZA Discussion Papers 1051, Institute for the Study of Labor..

Yang, F.,2009. Consumption over the life cycle: How different is housing? Review of Economic Dynamics 12, 423-443. 
Skill-Biased Technological Change and Homeownership

TABLE 1: HOMEOWNERSHIP RATES BY AGE (DATA)

Age of Household Head 1970s 1990s 1970s-1990s

\begin{tabular}{cccc}
\hline \hline $20-24$ & 23.9 & 17.6 & -6.3 \\
$25-29$ & 45.4 & 37.1 & -8.3 \\
$30-34$ & 64.3 & 55.0 & -9.3 \\
$35-39$ & 71.9 & 64.8 & -7.1 \\
$40-44$ & 75.9 & 71.7 & -4.2 \\
$45-49$ & 78.8 & 76.8 & -2.0 \\
$50-54$ & 79.7 & 80.0 & 0.3 \\
$55-59$ & 80.2 & 82.0 & 1.8 \\
$60-64$ & 78.9 & 83.4 & 4.5 \\
$65-69$ & 76.3 & 84.1 & 7.8 \\
$70-74$ & 72.9 & 83.7 & 10.8 \\
$75-79$ & 69.2 & 80.1 & 10.9 \\
Overall & 65.7 & 64.4 & -1.4 \\
\hline
\end{tabular}

TABLE 2: CALIBRATION TARGETS AND CORRESPONDING PARAMETERS

\begin{tabular}{|l|l|l|l|}
\hline & Parameter (annualized) & Target (annual) & Source \\
\hline Technology & $\alpha=0.32$ & $\frac{\left(r+\delta_{k}\right) K}{Y}=0.32$ & NIPA 1947-2008 \\
\hline Technology & $\delta_{d, o}=0.032, \delta_{d, r}=0.037$ & $\frac{I_{d}}{Y}=0.047, \frac{\delta_{d, r}}{\delta_{d, o}}=1.15$ & NIPA 1947-2008 \\
\hline Technology & $\delta_{k}=0.134$ & $\frac{I_{k}}{Y}=0.19$ & NIPA 1947-2008 \\
\hline Preferences & $\beta=0.949$ & $\frac{K}{Y}=1.65$ & NIPA 1947-2008 \\
\hline Preferences & $\lambda=0.856$ & $\frac{D_{o}+D_{r}}{Y}=1.08$ & NIPA 1947-2008 \\
\hline Min house & $d_{\min }=0.168$ & $64 \%$ Agg. Ownership & CPS 1976-1978 \\
\hline Initial assets & $X_{1} \sim U(0, \bar{X}), \bar{X}=0.28$ & $24 \%$ Young Ownership & CPS 1976-1978 \\
\hline LifeCycle Prof. & $h_{i}$ & 70 's Product. Profile & CPS 1970-1979 \\
\hline
\end{tabular}


Skill-Biased Technological Change and Homeownership

TABLE 3: HOMEOWNERSHIP RATES BY AGE (MODEL vs. DATA)

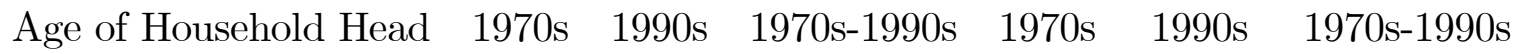

\begin{tabular}{ccccccc} 
& Data & Data & Data & Model & Model & Model \\
\hline \hline $20-24$ & 23.9 & 17.6 & -6.3 & 23.6 & 12.9 & -10.7 \\
$25-29$ & 45.4 & 37.1 & -8.3 & 41.3 & 31.6 & -9.7 \\
$30-34$ & 64.3 & 55.0 & -9.3 & 52.3 & 44.7 & -7.6 \\
$35-39$ & 71.9 & 64.8 & -7.1 & 62.1 & 59.3 & -2.8 \\
$40-44$ & 75.9 & 71.7 & -4.2 & 69.9 & 68.1 & -1.8 \\
$45-49$ & 78.8 & 76.8 & -2.0 & 77.1 & 76.6 & -0.6 \\
$50-54$ & 79.7 & 80.0 & +0.3 & 81.5 & 82.1 & +0.6 \\
$55-59$ & 80.2 & 82.0 & +1.8 & 83.9 & 85.3 & +1.3 \\
$60-64$ & 78.9 & 83.4 & +4.5 & 85.5 & 87.5 & +1.9 \\
$65-69$ & 76.3 & 84.1 & +7.8 & 86.6 & 89.3 & +2.7 \\
$70-74$ & 72.9 & 83.7 & +10.8 & 86.1 & 90.4 & +4.3 \\
$75-79$ & 69.2 & 80.1 & +10.9 & 83.2 & 88.8 & +5.6 \\
\hline
\end{tabular}

TABLE 4: HOMEOWNERSHIP RATES FOR YOUNG AND OLD (MODEL VS. DATA) Age Group 1970s 1990s 1970s-1990s 1970s 1990s 1970s-1990s

\begin{tabular}{ccccccc} 
& Data & Data & Data & Model & Model & Model \\
\hline \hline $20-44$ & 0.545 & 0.474 & -7.1 & 0.483 & 0.415 & -6.8 \\
$45-59$ & 0.795 & 0.794 & -0.1 & 0.807 & 0.811 & +0.4 \\
$60-79$ & 0.751 & 0.830 & +7.9 & 0.855 & 0.888 & +3.4 \\
\hline
\end{tabular}


Skill-Biased Technological Change and Homeownership

TABLE 5: HOMEOWNERSHIP RATES BY AGE (MODEL GE vs. PE)

\begin{tabular}{ccccccc} 
Age Group & $1970 \mathrm{~s}$ & $1990 \mathrm{~s}$ & $1970 \mathrm{~s}-1990 \mathrm{~s}$ & $1970 \mathrm{~s}$ & $1990 \mathrm{~s}$ & $1970 \mathrm{~s}-1990 \mathrm{~s}$ \\
& Model GE & Model GE & Model GE & Model PE & Model PE & Model PE \\
\hline \hline $20-24$ & 23.6 & 13.0 & -10.6 & 23.6 & 18.6 & -5.0 \\
$25-29$ & 41.3 & 31.6 & -9.7 & 41.3 & 36.0 & -5.3 \\
$30-34$ & 52.3 & 44.7 & -7.6 & 52.3 & 49.1 & -3.2 \\
$35-39$ & 62.1 & 59.3 & -2.8 & 62.1 & 60.3 & -1.8 \\
$40-44$ & 70.0 & 68.1 & -1.9 & 70.0 & 69.6 & -0.4 \\
$45-49$ & 77.2 & 76.6 & -0.6 & 77.2 & 78.2 & +1.0 \\
$50-54$ & 81.5 & 82.1 & +0.6 & 81.5 & 82.8 & +1.3 \\
$55-59$ & 84.0 & 85.3 & +1.3 & 84.0 & 85.8 & +1.8 \\
$60-64$ & 85.5 & 87.5 & +2.0 & 85.5 & 87.8 & +2.3 \\
$65-69$ & 86.6 & 89.3 & +2.7 & 86.6 & 89.5 & +2.9 \\
$70-74$ & 86.1 & 90.4 & +4.3 & 86.1 & 89.8 & +3.7 \\
$75-79$ & 83.2 & 88.8 & +5.6 & 83.2 & 88.2 & +5.0 \\
\hline
\end{tabular}




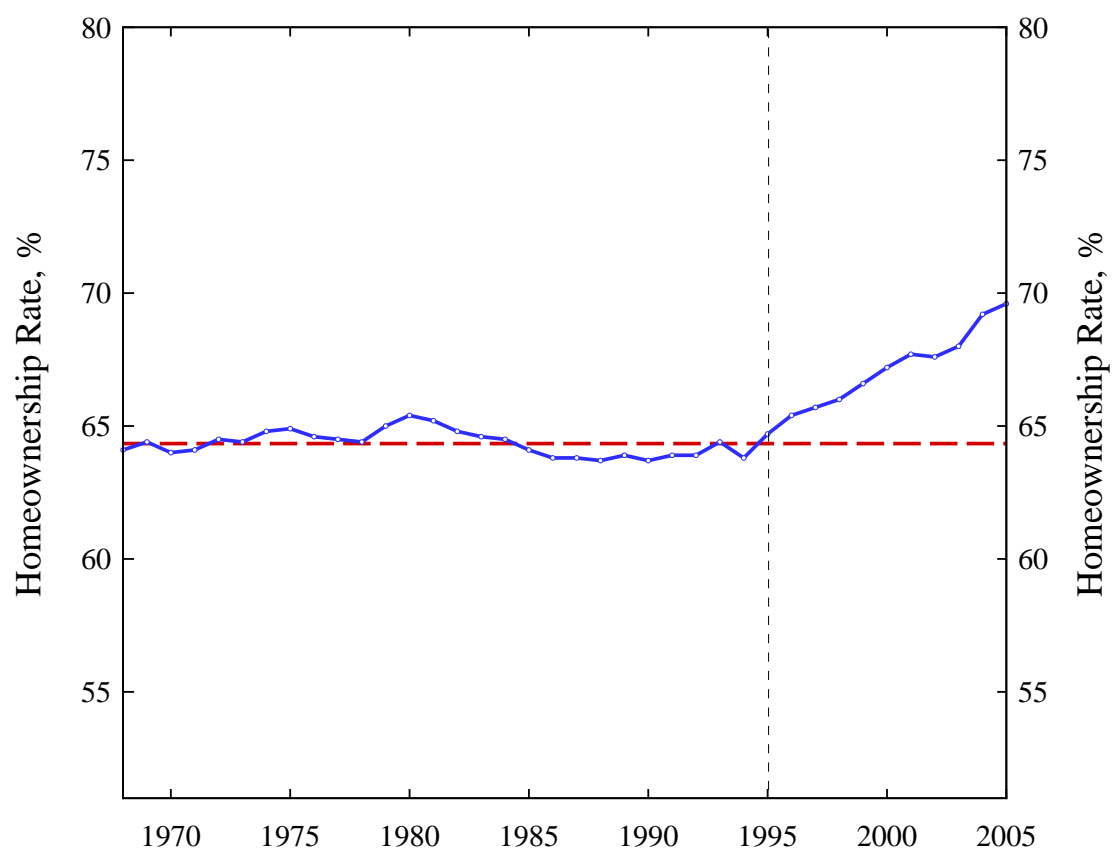

Figure 1: Aggregate Homeownership Rate

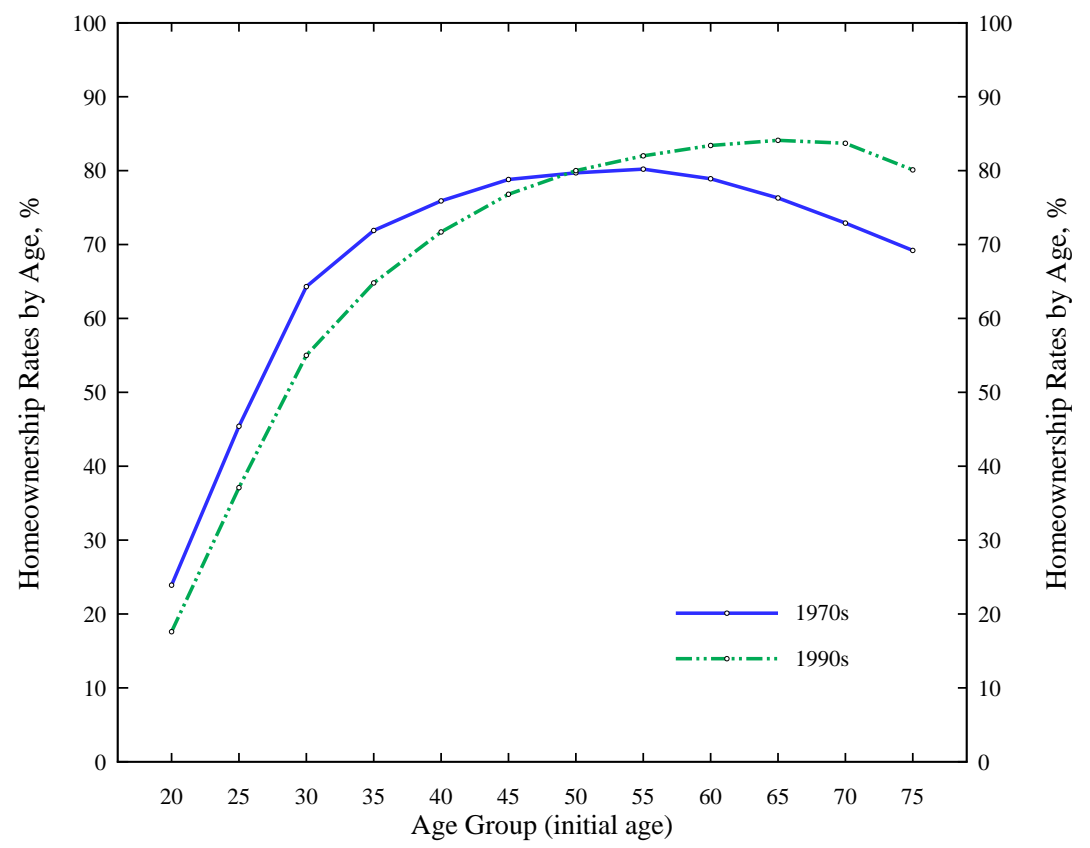

Figure 2: Homeownership Rates By Age: 70s vs. 90s 


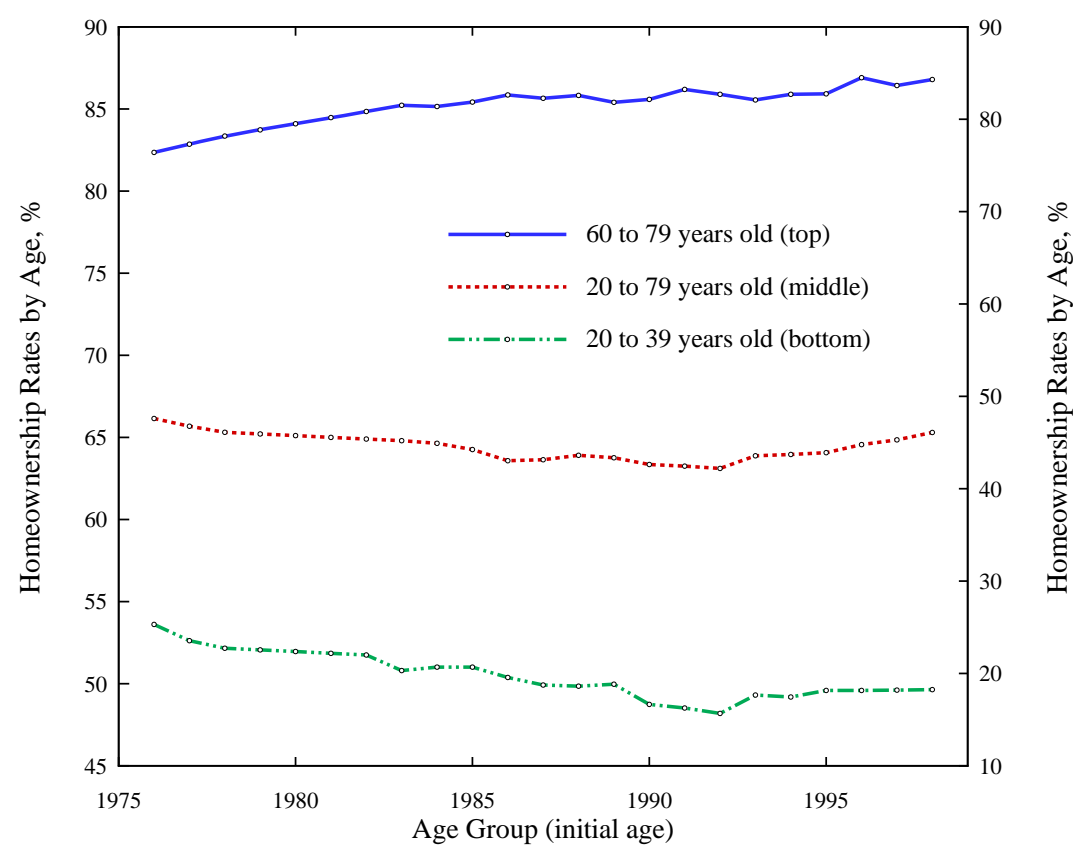

Figure 3: Homeownership Rates by Age Groups Over Time. We use interpolation for the years 1979-1982.

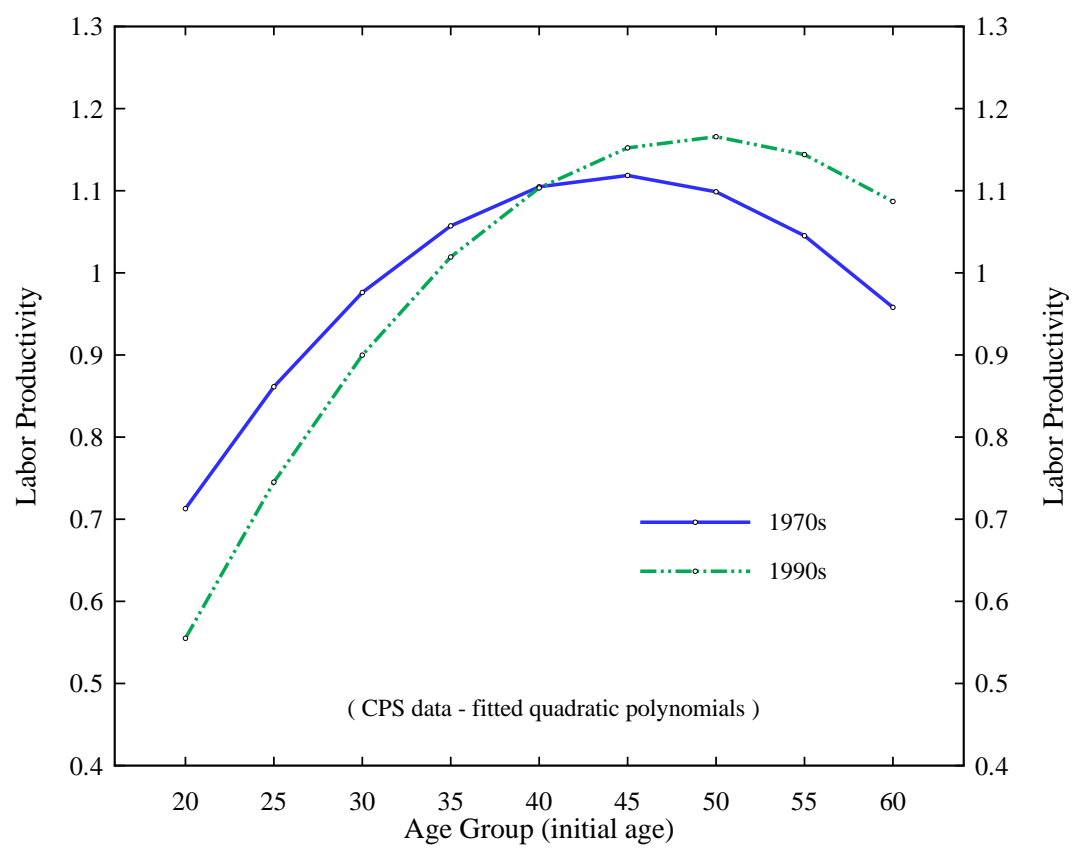

Figure 4: Productivity Profiles by Age in the Data. Computed as average hourly earnings for each age divided by average hourly earnings over all ages. 


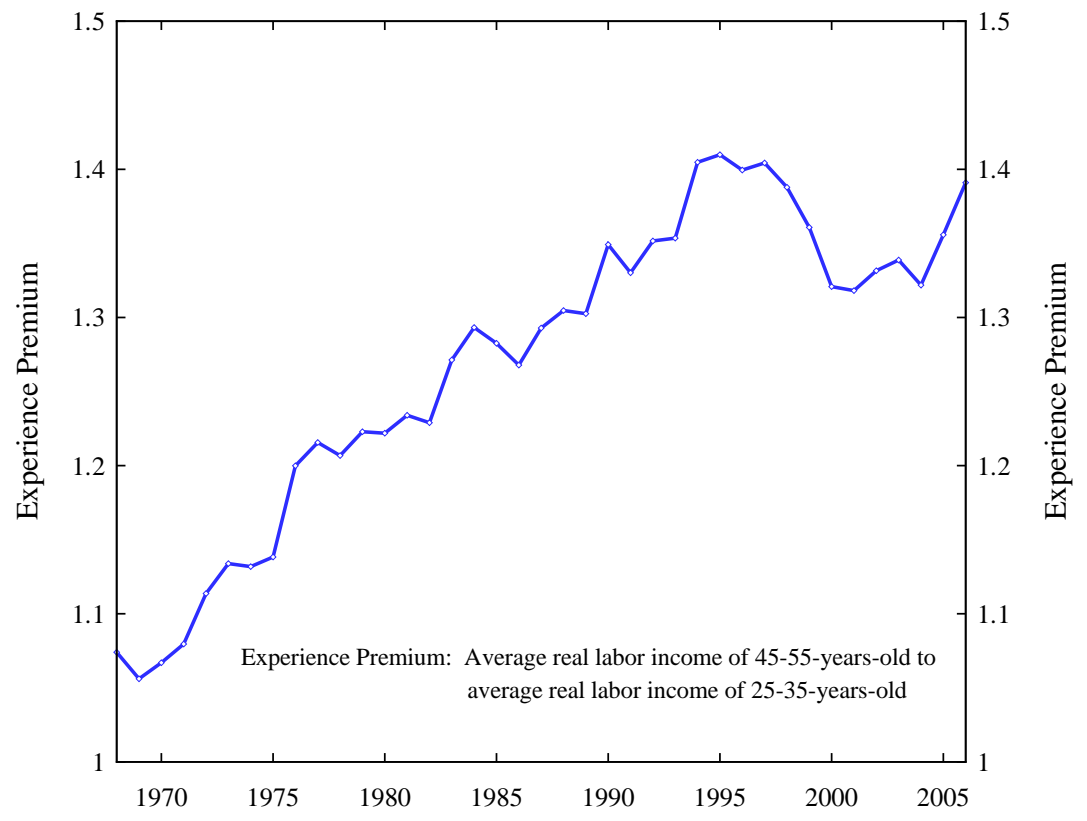

Figure 5: U.S. Experience Premium

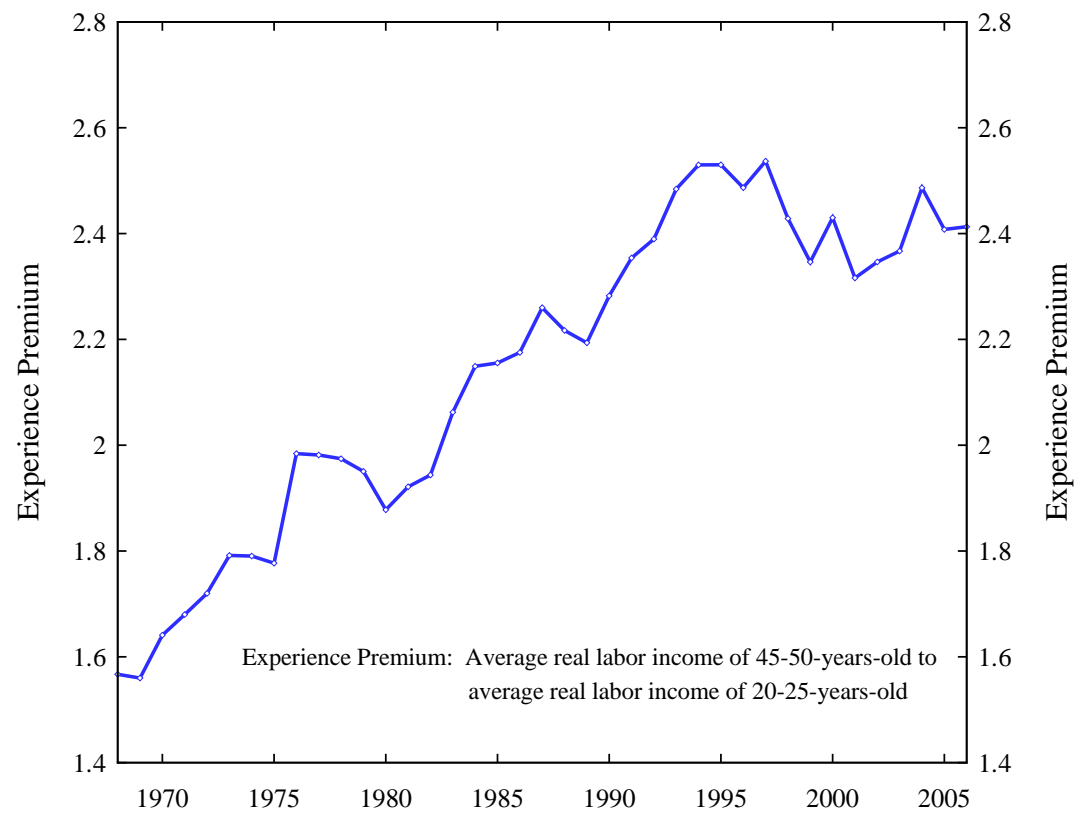

Figure 6: U.S. Experience Premium (Alternative Definition) 


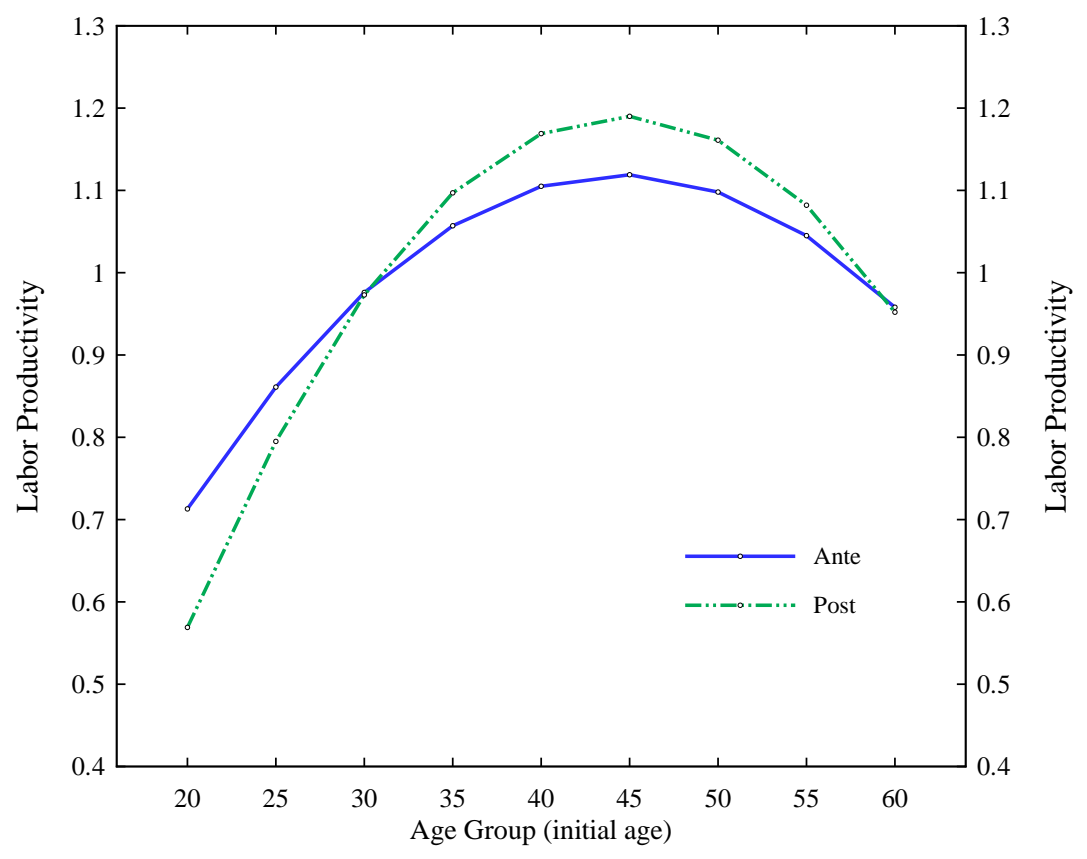

Figure 7: Productivity Profiles by Age in the Model. Computed as average hourly earnings for each age divided by average hourly earnings over all ages.

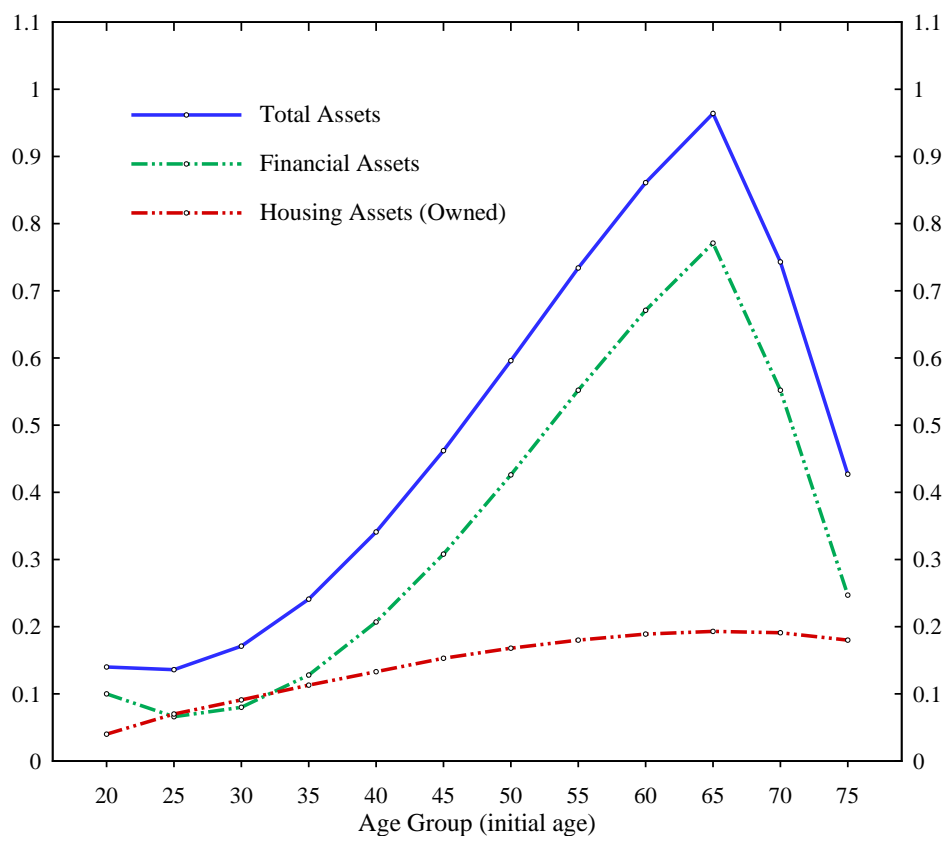

Figure 8: Asset Holdings by Age in the Economy Before SBTC (on average). 


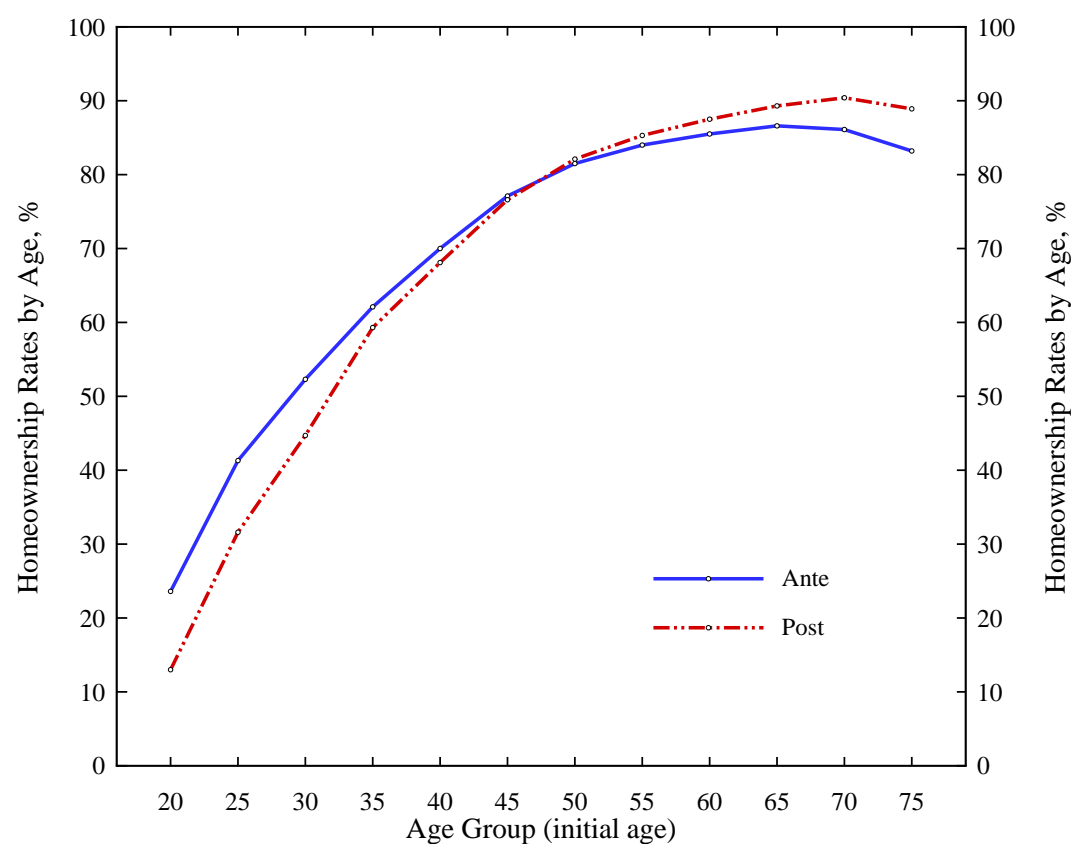

Figure 9: Homeownership Rates By Age in the Model

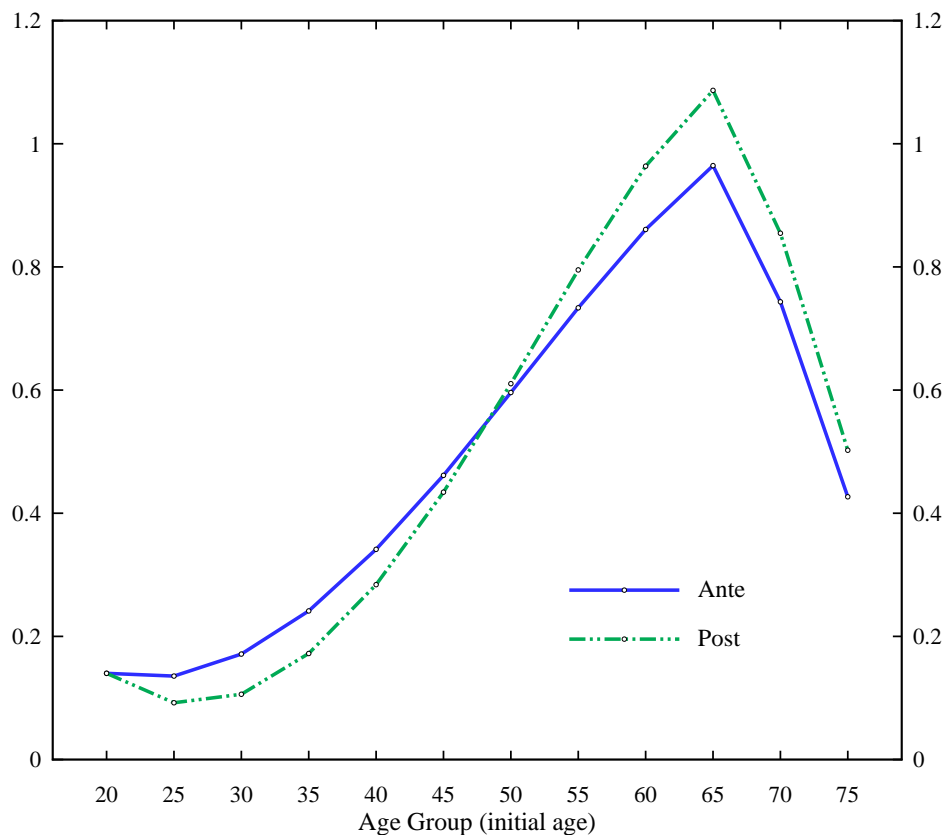

Figure 10: Total Assets by Age (on average). 


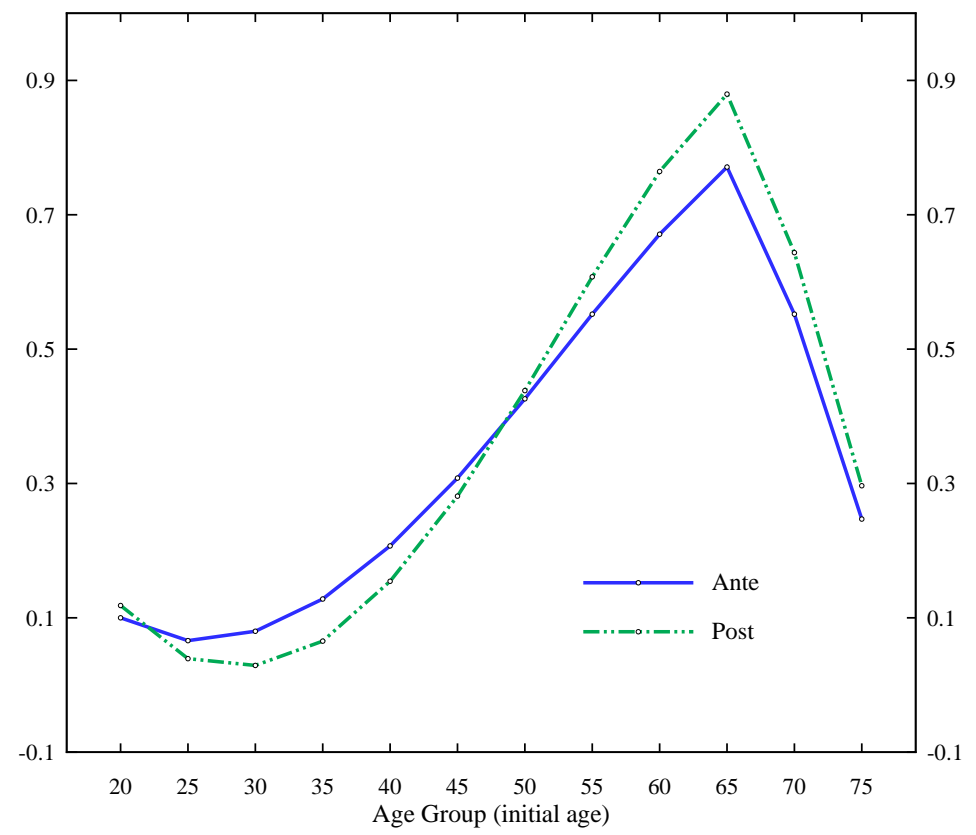

Figure 11: Financial Assets by Age (on average).

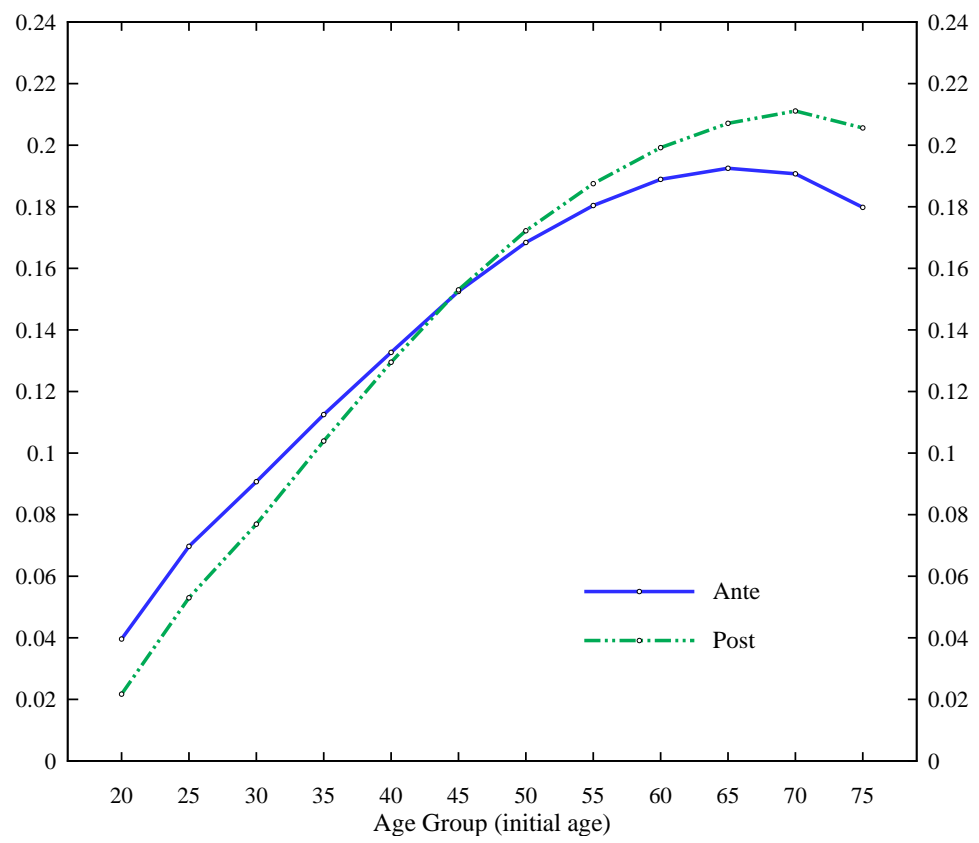

Figure 12: Owned Housing Assets by Age (on average). 


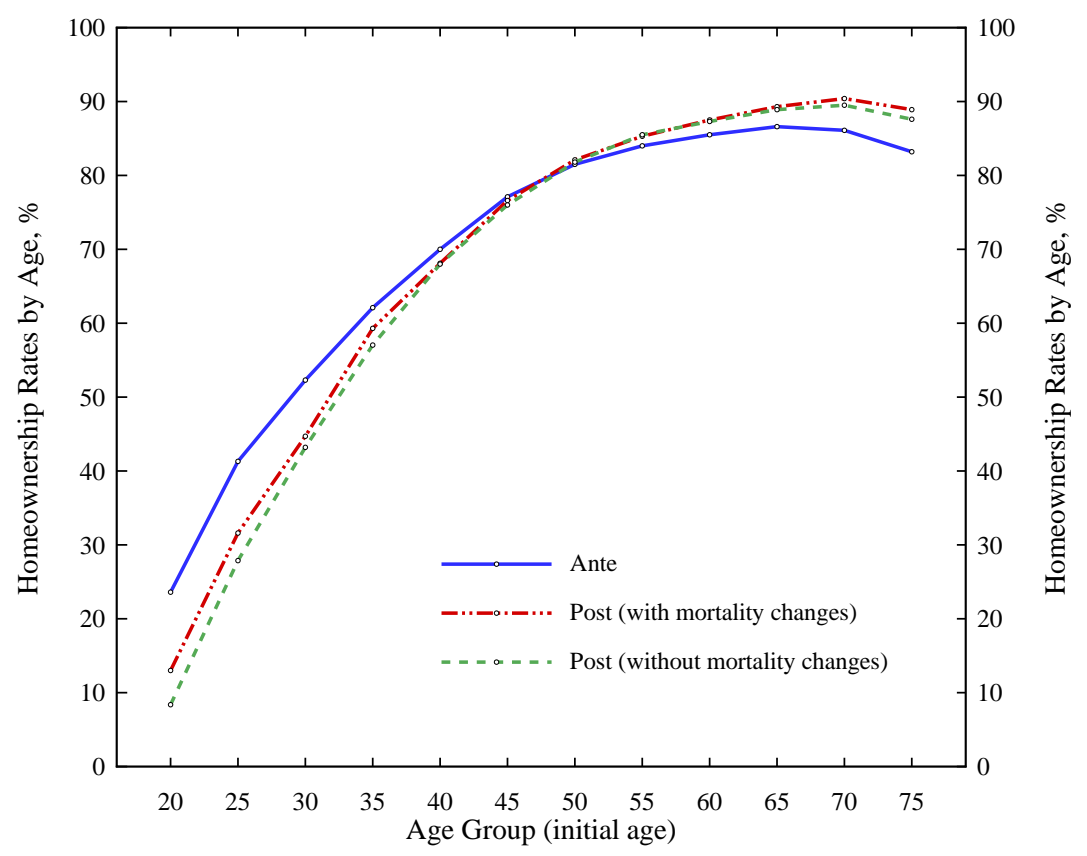

Figure 13: Homeownership Rates By Age in the Model: The Effect of Mortality Decrease

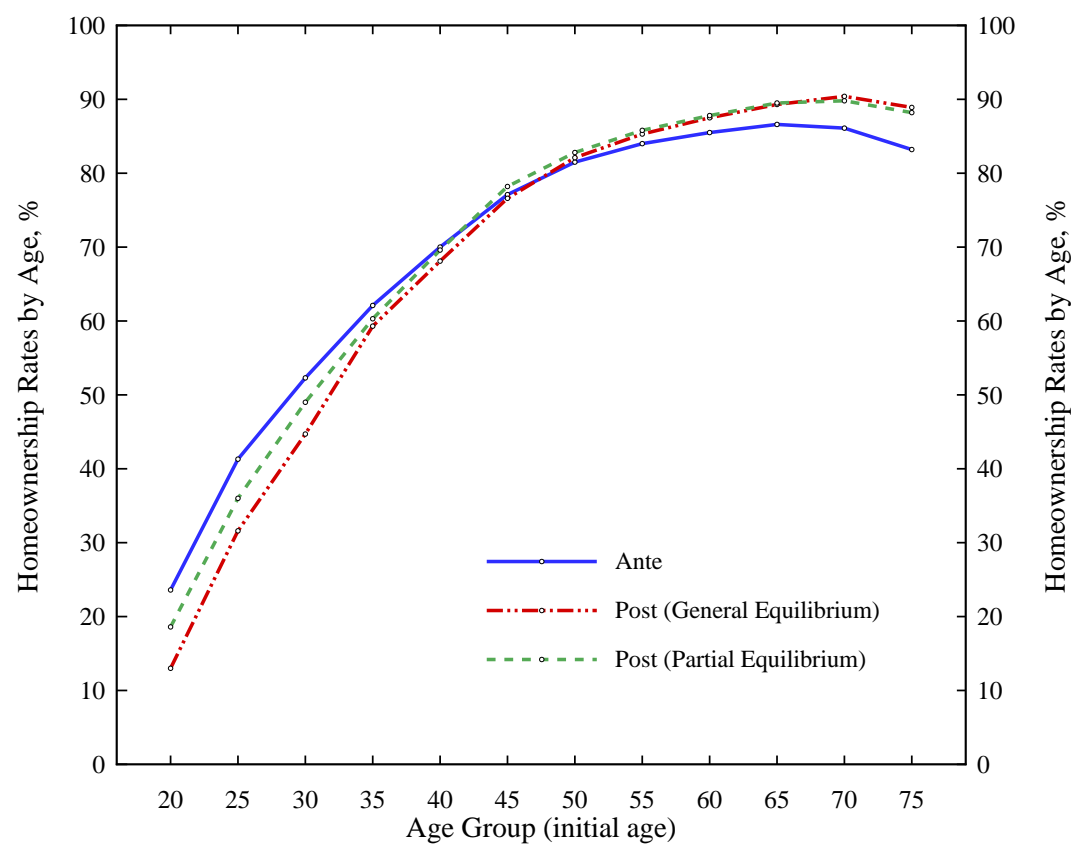

Figure 14: Homeownership Rates by Age in the Model: General Equilibrium Effects. 


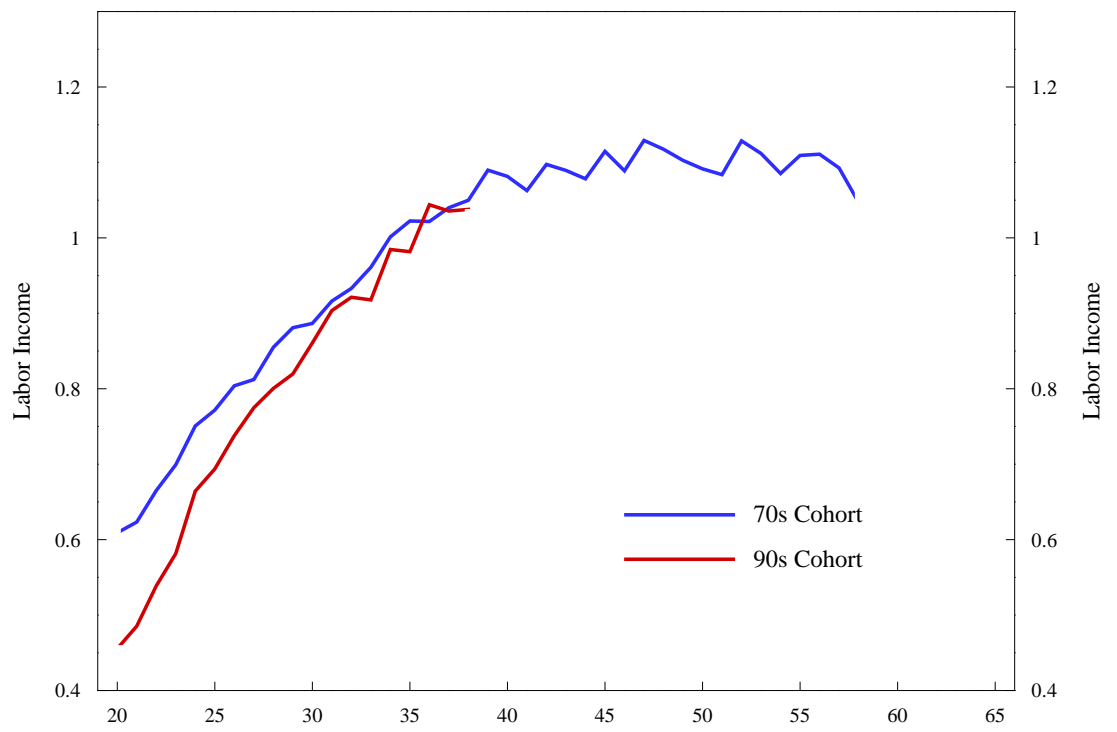

Figure 15: Productivity Profiles in the Data for the 70s and 90s cohorts. 